\title{
ANALYSIS OF AIR-BUBBLE PLUMES
}

\author{
by \\ Klas Cederwall \\ and \\ John D. Ditmars
}

W. M. Keck Laboratory of Hydraulics and Water Resources

Division of Engineering and Applied Science

CALIFORNIA INSTITUTE OF TECHNOLOGY

Pasadena, California

Report No. KH-R-24 <.1

September 1970 


\title{
ANALYSIS OF AIR-BUBBLE PLUMES
}

\author{
by \\ Klas Cederwall \\ (on leave from \\ Chalmers Institute of Technology, Göteborg, Sweden) \\ and \\ John D. Ditmars
}

Project Supervisor:

Norman H. Brooks

Funded by

Federal Water Quality Administration

U. S. Department of the Interior

and

The Swedish Board of Technical Development (STU)

\section{REFERENCE ROOM COPY}

W. M. Keck

Californi Engineering Laboratories

California Institute of Technology

W. M. Keck Laboratory of Hydraulics and Water Resources

Division of Engineering and Applied Science

California Institute of Technology

Pasadena, California 


\section{$\underline{\text { ABSTRACT }}$}

The air-bubble plume induced by the steady release of air into water has been analyzed with an integral technique based on the equations for conservation of mass, momentum and buoyancy. This approach has been widely used to study the behavior of submerged turbulent jets and plumes. The case of air-bubble induced flow, however, includes additional features. In this study the compressibility of the air and the differential velocity between the rising air bubbles and the water are introduced as basic properties of the air-bubble plume in addition to a fundamental coefficient of entrainment and a turbulent Schmidt number characterizing the lateral spreading of the air bubbles.

Theoretical solutions for two- and three-dimensional air-bubble systems in homogeneous, stagnant water are presented in both dimensional and normalized form and compared to existing experimental data. The further complication of a stratified environment is briefly discussed since this case is of great practical interest.

This paper is to be considered as a progress report, as future experimental verification of various hypotheses is needed. 


\section{TABLE OF CONTENTS}

Abstract

Notations iv

Introduction

$\begin{array}{ll}\text { Previous Studies } & 4\end{array}$

The Flow Model 5

1A. A Point Source in Homogeneous Ambient Fluid 7

1B. A Line Source in Homogeneous Ambient Fluid 16

2A. A Point Source with Zero Slip Velocity 20

2B. A Line Source with Zero Slip Velocity 26

Neglecting the Effect of Compressibility 29

Comparison with Experimental Data 32

Air Bubble Systems in Stratified Water 45

$\begin{array}{ll}\text { Conclusions } & 49\end{array}$

$\begin{array}{ll}\text { Acknowledgment } & 50\end{array}$

$\begin{array}{ll}\text { References } & 51\end{array}$ 


\section{NOTATIONS}

The main symbols used in this study are listed below. The SI - system is used consistently throughout this study.

\begin{tabular}{|c|c|}
\hline$y, r$ & lateral coordinates \\
\hline $\mathrm{x}$ & vertical coordinate \\
\hline$\Delta \mathrm{x}$ & virtual displacement of source \\
\hline $\mathrm{z}$ & normalized coordinate \\
\hline $\mathrm{b}$ & nominal half-width of plume. \\
\hline c & local concentration of air by volume \\
\hline$c_{m}$ & centerline value of $c$ \\
\hline $\mathrm{u}$ & local plume velocity \\
\hline $\mathrm{u}$ & centerline value of $u$ \\
\hline $\mathrm{u}_{\mathrm{b}}$ & slip velocity of air bubbles \\
\hline $\mathrm{H}$ & total depth \\
\hline $\mathrm{H}_{\mathrm{o}}$ & atmospheric pressure height \\
\hline h & depth of surface layer of horizontal flow \\
\hline$Q$ & volume flux \\
\hline$q$ & rate of air flow \\
\hline$q_{0}$ & $\mathrm{q}$ at the surface \\
\hline M & momentum flux \\
\hline B & buoyancy flux \\
\hline$\rho_{a}$ & density of ambient water \\
\hline$\rho_{0}$ & $\rho_{a}$ at source level in case of stratified water \\
\hline$\rho_{\mathrm{w}}$ & local density of water within plume \\
\hline
\end{tabular}


NOTATIONS (continued)

$\begin{array}{ll}\Delta \rho_{\mathrm{W}} & \max \left\{\rho_{\mathrm{w}}-\rho_{\mathrm{a}}\right\} \\ \rho_{\mathrm{m}} & \begin{array}{l}\text { local density of air-water mixture } \\ \text { within plume }\end{array} \\ \rho_{\text {air }} & \text { density of air } \\ \alpha & \text { coefficient of entrainment } \\ \lambda & \text { spreading ratio } \\ \mathrm{S}, \mathrm{G}, P \quad \text { plume parameters as defined in the text }\end{array}$




\section{INTRODUCTION}

Air-bubble systems have been used extensively and for a variety of purposes such as, pneumatic breakwaters, prevention of ice formation, as barriers against salt water intrusion in rivers and locks, for stopping the spreading of oil spills on the water surface, for reduction of underwater explosion waves and for agitation and mixing operations in process industries. However, the technique may also be used for destratification and water quality control management of lakes and reservoirs in which case the characteristics of the air-bubble plume are of more interest than the induced horizontal flow in the surface layer.

Despite the wide range of practical applications, no theory has been developed to give a satisfactory description of the hydrodynamics of air-bubble systems. The reason is of course that the very details of the structure of this two-phase flow phenomenon are very complex. However, as will be demonstrated, the gross behavior of the air-bubble plume may be analysed sufficiently well for design purposes.

The release of air at some depth in a body of water gives rise to a large scale circulation but also mixing and reaeration of the water, see Fig. 1. The mixing is primarily within the plume generated by the rising bubbles but over-all mixing may also be caused by the agitation of the whole system as in the case of batch-mixing, that is when the water body is small relative to the air-bubble plume. We will treat the case of an air-bubble plume in an infinite fluid. 


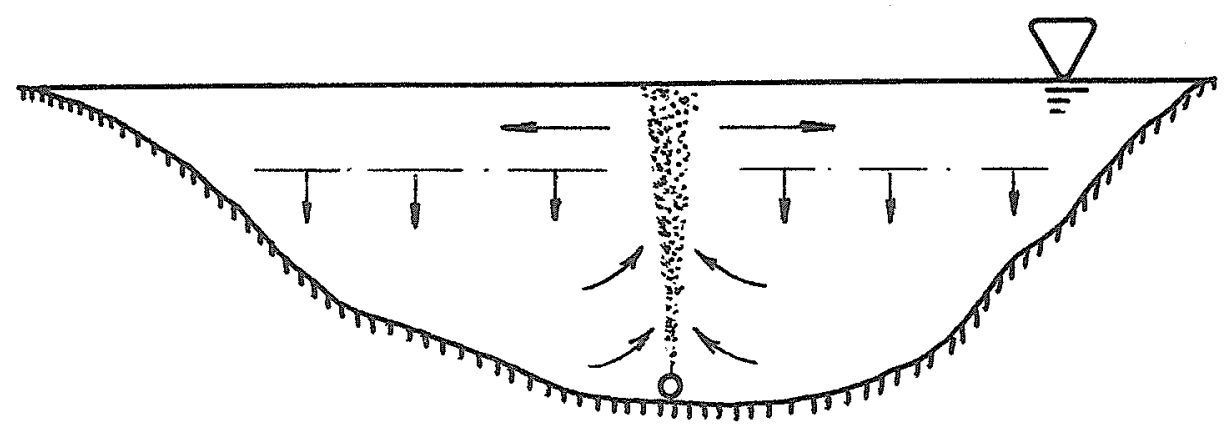

a. Over-all circulation in a homogeneous reservoir.

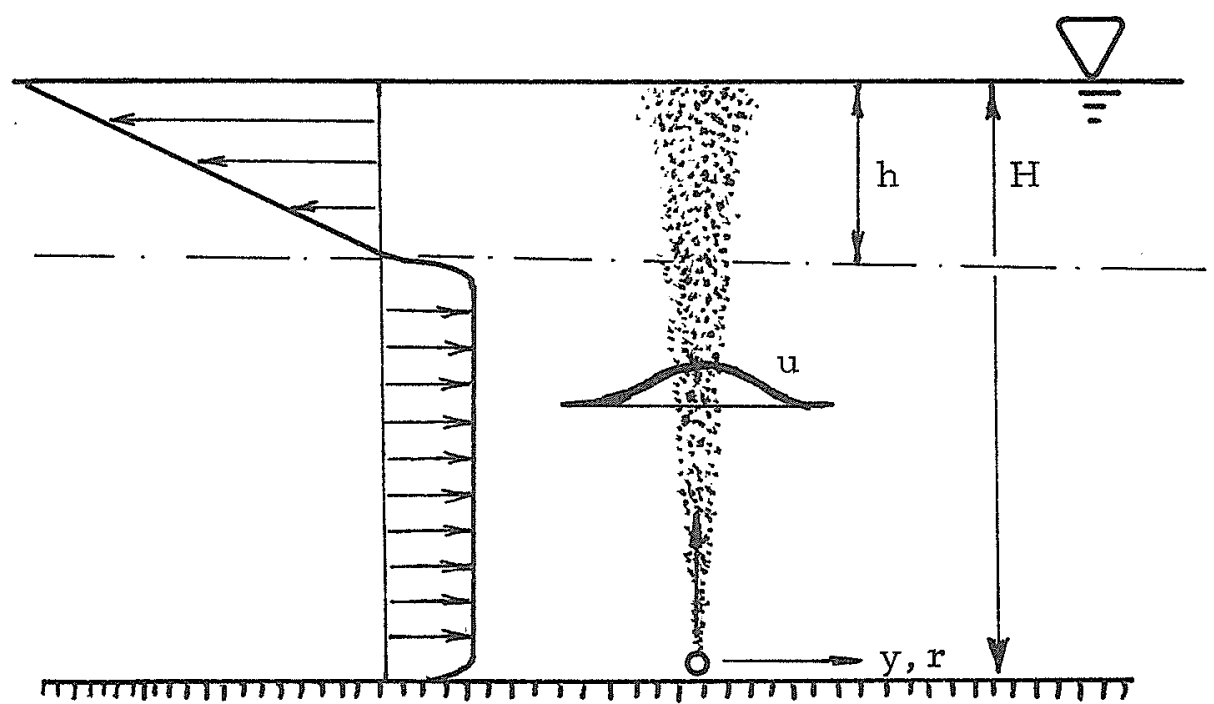

b. Velocity field close to the air-bubble plume.

Fig. 1 Schematic representation of flow induced by the release of air-bubbles in homogeneous, stagnant water. 
Natural water bodies such as lakes and impoundments are usually stratified. The thermal (density) stratification is a factor. which effectively controls convection and diffusion in the lake. The most stable stratification conditions exist during the summer months when the lake or reservoir exhibits large thermal gradients. As a result the water quality of the lower layers may be reduced significantly since the dissolved oxygen content is no longer replenished by surface reaeration. Artificial mixing may then be an effective way of improving water quality of the water body. There are several methods of accomplishing destratification; the use of air-curtain systems seems to be a good alternative to mechanical pumping. However, little is known about the air-bubble induced circulation in stratified waters. The final part of this report will discuss this problem. 


\section{PREVIOUS STUDIES}

The air flow discharged into water rapidly expands, due to the pressure drop across the nozzle, and breaks up into bubbles of discrete size. This initial formation of the gas bubbles has been studied both theoretically and experimentally, see for instance, Davidson and Schiler (1960). Several studies on the motion of gas bubbles in liquid are reported in the literature. Haberman and Morton (1954) carried out a comprehensive investigation on the rise velocity of single air bubbles in still water.

The similarity between the air-bubble plume and a simple buoyant plume was first pointed out by Taylor (1955) in a discussion on the use of pneumatic breakwaters. Bulson (1961) derived semiempirical relations for maximum velocity and thickness of the layer of horizontal surface flow. Sjöberg (1967) and Kobus (1968) have studied the flow induced by air-bubble systems both experimentally and theoretically using the similarity to jet and plume mixing. The present theory will be compared to the experimental data reported by Kobus (1968). 


\section{THE FLOW MODEL}

The interaction between the rising bubbles and the ambient water is a complex function depending on several parameters. The idealized model we will use is based on the following selection of significant variables:

$q_{0}$ the volume rate of air flow at atmospheric pressure (in $\mathrm{m}^{3} / \mathrm{s}$ for point source and in $\mathrm{m}^{2} / \mathrm{s}$ for line source)

$\mathrm{u}_{\mathrm{b}}$ the differential velocity of the air bubbles relative to the water (slip velocity)

$\frac{\rho_{a}-\rho_{a i r}}{\rho_{a}} g$ apparent gravity where $\rho_{a}$ and $\rho_{\text {air }}$ are the density of the ambient water and the air respectively and $g$ the acceleration of gravity

$\mathrm{H}$ the depth above the air flow source

$H_{0}$ piezometric head equivalent to the atmospheric pressure $\left(\mathrm{H}_{\mathrm{O}}\right.$ is regarded as a constant $\left.\approx 10.4 \mathrm{~m}\right)$

$u_{b}$, the terminal rise velocity of an air-bubble in stagnant, ambient water, is assumed to be attained near the source and then remain constant throughout the depth and to be equal for all bubbles. This has been found to be a good approximation despite the fact that the bubbles probably vary in size in the plume. *

The expansion of the air bubbles as they rise through the water is neither adiabatic nor truly isothermal but an intermediate process. We will here for simplicity assume isothermal conditions - the

For example, Haberman and Morton show that in the range of diameters $10^{-3}$ to $10^{-2} \mathrm{~m}, \mathrm{u}_{\mathrm{b}}$ changes only from about 0.20 to $0.30 \mathrm{~m} / \mathrm{s}$, see discussion in a later section of this paper. 
ambient water is a heat sink - although the expansion of at least large bubbles are likely to be nearly adiabatic. However, it was found that the choice of gas law has no significant effect on the result of the theoretical analysis. Hence, if $x$ is the vertical coordinate originating from the source and $q(x)$ the local volume rate of air flow at level $x$, isothermal conditions give

$$
q(x)\left(H_{0}+H-x\right)=q_{0} \cdot H_{0}
$$

In particular at the source level

$$
q(x=0)=q_{0} \cdot \frac{H_{0}}{H_{0}+H}
$$

Dimensional arguments imply that we have two non-dimensional parameters to characterize the flow phenomenon

$$
\frac{u_{b}^{3} \cdot H}{q_{0} \frac{\rho_{a}-\rho_{a i r}}{\rho_{a}} g} \text { or } \frac{u_{b}^{3}}{q_{0} \frac{\rho_{a}^{-\rho_{a i r}}}{\rho_{a}} g} \text { and } \frac{H}{H_{0}} \quad\left(\begin{array}{l}
\text { for point or } \\
\text { line source } \\
\text { respectively }
\end{array}\right)
$$

The first parameter is a "design parameter" of the air-bubble system and the second one a scaling parameter. As we will see later both these parameters will appear in principle in the form given above when normalizing the general equations and introducing proper boundary conditions.

When the slip velocity, $u_{b}$, goes to zero we have a limiting case of interest. Small values of $u_{b}$ implies that small bubbles are produced at the source. Considering the circulation induced by the air bubble system this limiting case corresponds to the "ideal design" as will be demonstrated later on. 
When the aix-bubbles rise through the ambient water, the induced vertical flow is likely to resemble the process of turbulent diffusion from a submerged source of buoyancy as indicated originally by Taylor (1955). This similarity with the plume case is the basis for the present work. Hence, to solve the problem we will use the integral technique first proposed by Morton, Taylor and Turner (1956). The study is restricted to the zone where the horizontal flow near the water surface does not affect the vertical flow, that is for $\mathrm{x}<\mathrm{H}-\mathrm{h}$, see Fig. 1. It has been found empixically that $h$ is approximately $0.25 \mathrm{H}$ in the two-dimensional case and somewhat less for a pointsource.

\section{A. A Point Source in Homogeneous Ambient Fluid}

The rate of entrainment at the edge of the plume is assumed to be proportional to the mean axial plume velocity. Furthermore, we assume that the lateral profiles of velocity and density deficiency are similar at all heights and that they can be approximated by Gausian distributions. Hence, for the velocity

$$
u=u_{m} \cdot e^{-r^{2} / b^{2}}
$$

where $u$ is a local mean velocity and $u_{m}$ the centerline velocity. $b$ is the nominal half-width of the plume related to the standard deviation of the velocity distribution by

$$
2 \sigma=\sqrt{2} \mathrm{~b}
$$

The density distribution is given by

$$
\left(p_{\mathrm{a}}-\rho_{\mathrm{m}}\right)=\Delta p_{\mathrm{m}} \cdot \mathrm{e}^{-\mathrm{r}^{2} /(\lambda \mathrm{b})^{2}}
$$


$\rho_{m}$ is the local density of the air-water mixture and $\rho_{a}$ the density of the ambient fluid. $\Delta \rho_{\mathrm{m}}$ is then the centerline density difference between ambient water and air-water mixture within the plume at a particular level. $1 / \lambda^{2}$ is the turbulent Schmidt number.

Making the Boussinesq assumption that density differences may be neglected except in buoyancy terms, the expression for the volume flux is written

$$
Q=\int_{0}^{\infty} 2 \pi u r d r=2 \pi u_{m} \int_{0}^{\infty} e^{-r^{2} / b^{2}} r d r=\pi u_{m} \cdot b^{2}
$$

The rate of entrainment, $\frac{d Q}{d x}$, is assumed to be

$$
\frac{d Q}{d x}=2 \pi b \alpha u_{m}
$$

where $\alpha$ is the coefficient of entrainment assumed constant.

Eq. (7) gives

$$
\frac{d}{d x}\left(u_{m} b^{2}\right)=2 \alpha u_{m} \cdot b
$$

The buoyancy flux of the air-water flow is written

$$
B=\int_{0}^{\infty} 2 \pi\left(u+u_{b}\right)\left(\rho_{a}-\rho_{m}\right) r d r=\pi u_{m} \Delta \rho_{m} \frac{\lambda^{2} b^{2}}{1+\lambda^{2}}+\pi u_{b} \Delta \rho_{m} \lambda^{2} b^{2}
$$

The buoyancy flux at any level $x$ is found using Eq. (1) to be

$$
B=q_{0}\left(\rho_{a}-\rho_{\text {air }}\right) \frac{H_{o}}{H_{0}+H-x}
$$

As $\rho_{\text {air }}<<\rho_{a}$, B may be written

$$
B=q_{0} \rho_{a} \frac{H_{0}}{H_{0}+H-x}
$$


and hence we arrive at the following buoyancy flux relation

$$
\pi u_{m} \Delta \rho_{m} \frac{\lambda^{2} b^{2}}{1+\lambda^{2}}+\pi u_{b} \Delta \rho_{m} \lambda^{2} b^{2}=q_{0} \rho_{a} \frac{H_{0}}{H_{o}+H-x}
$$

Similarly, for the momentum flux with $\rho_{\mathrm{m}} \approx \rho_{\mathrm{a}}$ according to Boussinesq assumption

$$
M=\int_{0}^{\infty} 2 \pi u^{2} \rho_{a} r d r=\frac{\pi u_{m}^{2} \rho_{a} b^{2}}{2}
$$

The driving force of the plume is the buoyancy, and the momentum flux equation is

$$
\frac{d M}{d x}=\int_{0}^{\infty} 2 \pi\left(\rho_{a}-\rho_{m}\right) g r d r=\pi g \Delta \rho_{m} \lambda^{2} b^{2 a}
$$

which combined with Eq. (13) yields

$$
\frac{d\left(u_{m}^{2} b^{2}\right)}{d x}=2 g \frac{\Delta \rho_{m}}{\rho_{a}} \lambda^{2} b^{2}
$$

Substituting $\frac{\Delta \rho_{m}}{\rho_{a}}$ from Eq. (15) into Eq. (12) gives us two equations to solve

$$
\begin{gathered}
\frac{d\left(u_{m} b^{2}\right)}{d x}=2 \alpha u_{m} b \\
\frac{d\left(u_{m}^{2} b^{2}\right)}{d x}=\frac{2 g q_{0} H_{o}}{\pi\left(H_{o}+H-x\right)\left(\frac{u_{m}}{1+\lambda^{2}}+u_{b}\right)}
\end{gathered}
$$

Eqs. (16) and (17) must be solved to obtain the centerline values $\mathrm{u}_{\mathrm{m}}$ and $\mathrm{b}$ as a function of $\mathrm{x}$ and $\Delta \rho_{\mathrm{m}}$ is then found from Eq. (12). Since a solution to the differential equations cannot be obtained in closed analytical form, a numerical integration has to be carried out. The numerical solution follows from a direct step-by-step integration of 
these two equations

$$
\begin{aligned}
& \frac{d u_{m}}{d x}=\frac{2 g q_{o} H_{o}}{\pi u_{m} b^{2}\left(H_{o}+H-x\right)\left(\frac{m}{1+\lambda^{2}}+u_{b}\right)}-\frac{2 \alpha u_{m}}{b} \\
& \frac{d b}{d x}=2 \alpha-\frac{g q_{o} H_{o}}{\pi u_{m}^{2} b\left(H_{o}+H-x\right)\left(\frac{m}{1+\lambda^{2}}+u_{b}\right)}
\end{aligned}
$$

Near $x=0, u_{m}>>u_{b}$ and hence Eqs. (18) and (19) take the following form

$$
\begin{aligned}
& \frac{d u_{m}}{d x}=\frac{2 g q_{o} H_{o}\left(1+\lambda^{2}\right)}{\pi u_{m}^{2} b^{2}\left(H_{o}+H-x\right)}-\frac{2 \alpha u_{m}}{b} \\
& \frac{d b}{d x}=2 \alpha-\frac{g q_{o} H\left(1+\lambda^{2}\right)}{\pi u_{m}^{3} b\left(H_{o}+H-x\right)}
\end{aligned}
$$

Eqs. (20 and (21) are the governing equations for a plume due to a source of buoyancy only. The solution to the simple plume equations provides us with the starting conditions for the numerical integration.

$$
\begin{gathered}
b=\frac{6}{5} \alpha x \\
u_{m}=\left[\frac{25 \mathrm{~g} \mathrm{q}_{\mathrm{o}} \mathrm{H}_{\mathrm{o}}\left(1+\lambda^{2}\right)}{24 \alpha^{2} \pi\left(\mathrm{H}_{\mathrm{o}}+\mathrm{H}\right)}\right]^{\frac{1}{3}} \mathrm{x}^{-\frac{1}{3}}
\end{gathered}
$$

$x=0$ corresponds to the "mathematical origin".

For comparison with mathematical data we have to displace virtually the position of the real source a distance $\Delta x$ downwards considering the finite dimensions of the source and pressure drop effect on the initial expansion of the air-bubbles. Kobus (1968) found $\Delta x=0.8 \mathrm{~m}$ being a reasonable value for both two- and three-dimensional 
air-bubble plumes and for a wide range of $q_{0} \cdot *$ Hence, we will use this value when comparing his experimental data with the present theory. Normalized Equations

The dimensional equations are normalized by the following procedure. Let

$$
\begin{aligned}
& F=\frac{\mathrm{g}_{\mathrm{o}} \mathrm{H}_{\mathrm{o}}}{\pi} \\
& \mathrm{Y}=\mathrm{H}_{\mathrm{o}}+\mathrm{H}-\mathrm{x} \\
& \mathrm{V}=\mathrm{u}_{\mathrm{m}} \cdot \mathrm{b} \\
& \mathrm{W}=\mathrm{u}_{\mathrm{m}} \cdot \mathrm{b}^{2}
\end{aligned}
$$

$V^{2}$ and $W$ are then proportional to the momentum flux and mass flux, respectively. Eqs. (16) and (17) may now be written

$$
\begin{gathered}
\frac{d W}{d Y}=-2 \alpha V \\
\frac{d V^{2}}{d Y}=-2 \frac{F}{Y\left(\frac{V^{2}}{W\left(1+\lambda^{2}\right)}+u_{b}\right)}
\end{gathered}
$$

If $V, W$ and $Y$ have the normalized forms $V, w$ and $y$ we may write

$$
\begin{aligned}
& V=F^{a_{1}} \alpha^{a_{2}}\left(1+\lambda^{2}\right)^{a_{3}} u_{b}^{a_{4}} v \\
& W=F^{b_{1}} \alpha^{b_{2}}\left(1+\lambda^{2}\right)^{b_{3}} u_{b}^{b_{4}} w \\
& Y=F^{c_{1}} \alpha^{c_{2}}\left(1+\lambda^{2}\right)^{c_{3}} u_{b}^{c_{4}} y
\end{aligned}
$$

and by use of Eqs. (25) and (26) we can identify the powers of Eqs. (27), Hence,

\footnotetext{
* In these experiments the water depth ranged from 2 to $4.5 \mathrm{~m}$ and the diameter of the orifice from $5 \cdot 10^{-4}$ to $5 \cdot 10^{-3} \mathrm{~m}$.
} 


$$
\begin{aligned}
& \mathrm{V}=\mathrm{F}^{\frac{1}{2}} \mathrm{u}_{\mathrm{b}}^{-\frac{1}{2}} \mathrm{v} \\
& \mathrm{W}=\mathrm{F}\left(1+\lambda^{2}\right)^{-1} \mathrm{u}_{\mathrm{b}}^{-2} \mathrm{w} \\
& \mathrm{Y}=\mathrm{F}^{\frac{1}{2}} \alpha^{-1}\left(1+\lambda^{2}\right)^{-1} \mathrm{u}_{\mathrm{b}}^{-3 / 2} \mathrm{y}
\end{aligned}
$$

and the normalized differential equations are written

$$
\begin{array}{r}
\frac{d w}{d y}=-2 v \\
\left(v^{2}+w\right) \frac{d v^{2}}{d y}=-2 \frac{w}{y}
\end{array}
$$

with the following initial conditions

$$
\begin{gathered}
\mathrm{v}=0 \\
\mathrm{w}=0 \\
\text { at } \mathrm{y}=\frac{\mathrm{H}_{\mathrm{o}}+\mathrm{H}}{\mathrm{F}^{\frac{1}{2}} \alpha^{-1}\left(1+\lambda^{2}\right)^{-1} \mathrm{u}_{\mathrm{b}}^{-3 / 2}}
\end{gathered}
$$

If we define $Y=\left(\mathrm{H}_{\mathrm{O}}+\mathrm{H}\right) \mathrm{z}$, that is

$$
z=\frac{F^{\frac{1}{2}} \alpha^{-1}\left(I+\lambda^{2}\right)^{-1} u_{b}^{-3 / 2}}{H_{0}+H} \quad y=\frac{H_{o}+H-x}{H_{0}+H}
$$

and introduce a source parameter $G$ defined by

$$
G=\frac{H_{0}+H}{F^{\frac{1}{2}} \alpha^{-1}\left(1+\lambda^{2}\right)^{-1} u_{b}^{-3 / 2}}
$$

we arrive at the following set of normalized equations

$$
\begin{aligned}
& \frac{d w}{d z}=-2 G v \\
& \left(v^{2}+w\right) \frac{d v^{2}}{d z}=-2 \frac{w}{z}
\end{aligned}
$$


Eqs. (34) and (35) then have to be integrated from $z=1$ to $z^{\min }=\mathrm{P}=\frac{\mathrm{H}_{0}}{\mathrm{H}_{\mathrm{O}}+\mathrm{H}}$ for a given value of $G$. $P$ is a scaling parameter and the flow phenomenon is a two parameter problem as indicated by the dimensional analysis. $u_{m}$, b and $x$ follow from

$$
\begin{gathered}
u_{m}=\left(1+\lambda^{2}\right) u_{b} \frac{v^{2}}{w} \\
b=F^{\frac{1}{2}}\left(1+\lambda^{2}\right)^{-1} u_{b}^{-3 / 2} \frac{w}{v} \\
x=\left(H_{0}+H\right)(1-z)
\end{gathered}
$$

Eqs. (34) and (35) may be expanded to give

$$
\begin{gathered}
\frac{d w}{d z}=-2 G v \\
\frac{d v}{d z}=-\frac{w}{z\left(v^{3}+w v\right)}
\end{gathered}
$$

Since $v=w=0$ at the start of the calculation, that is for $z=1$, we have to find a starting solution for the integration procedure. Similar to the dimensional case we use the simple plume equations. Substituting Eqs. (36) into Eqs. (22) and (23) gives

$$
\begin{aligned}
& v=\left(\frac{9}{5}\right)^{\frac{1}{3}} G^{\frac{1}{3}}(1-z)^{\frac{2}{3}} \\
& w=\frac{6}{5}\left(\frac{9}{5}\right)^{\frac{1}{3}} G^{4 / 3}(1-z)^{5 / 3}
\end{aligned}
$$

These are the starting solutions for the normalized equations. Similar to the dimensional case we have as starting condition that $v^{2}>>$ w as for $u_{m}>>u_{b}$ which is a restriction to the choice of step length for the numerical integration. 


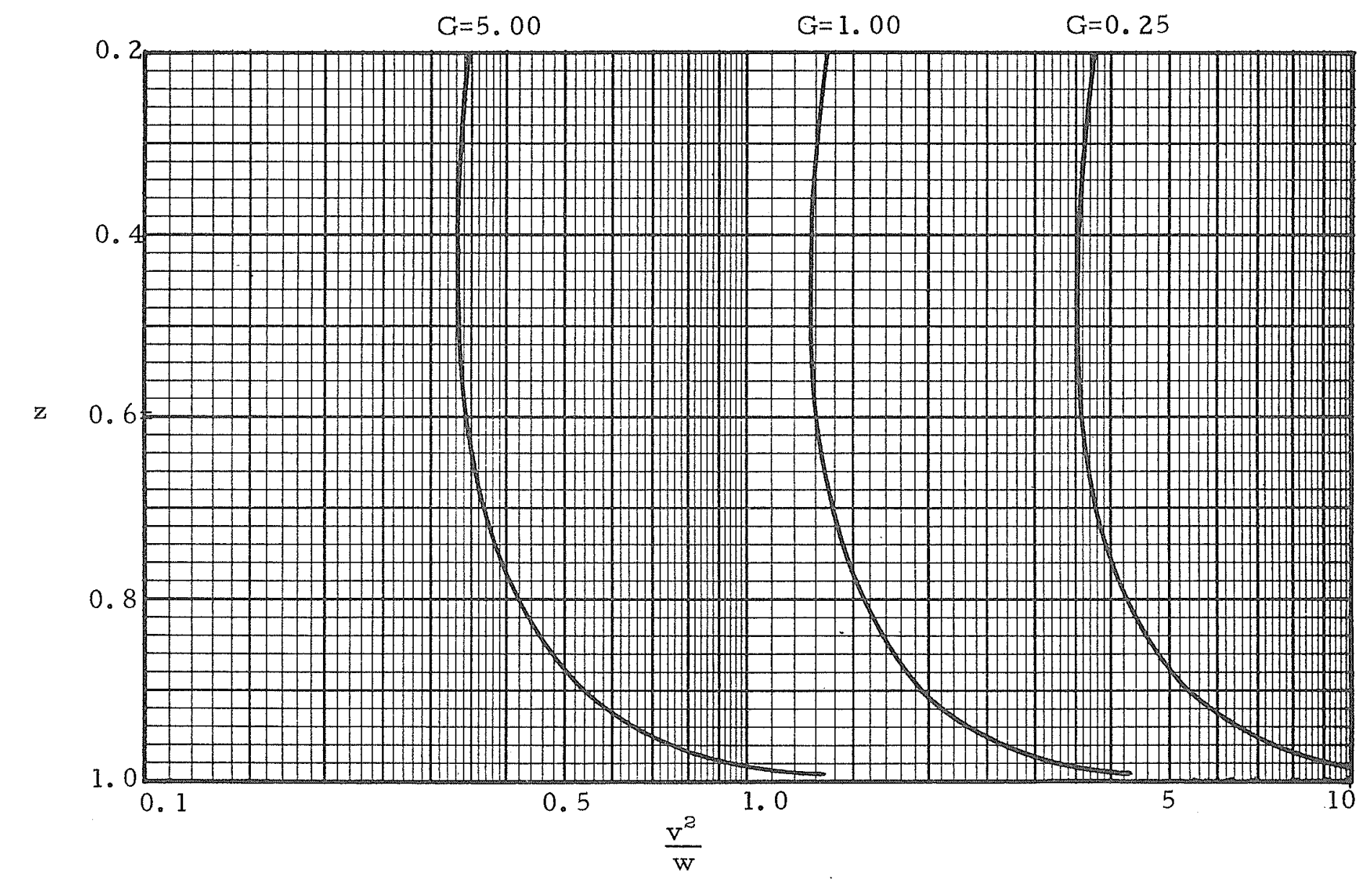

1

Fig. 2. General solution of the three-dimensional air-bubble plume for G equal 0.25 , 1.0 and 5.00. The centerline velocity $u_{m}=\left(1+\lambda^{2}\right) u_{b} \frac{v^{2}}{w}$. 
$0 . 2 \longdiv { 1 0 }$

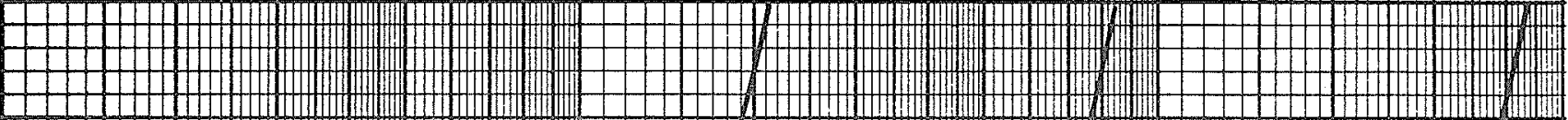

1210

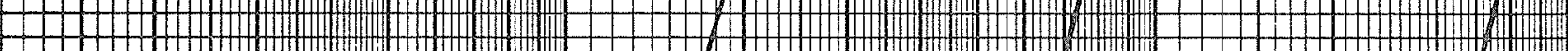

0.4

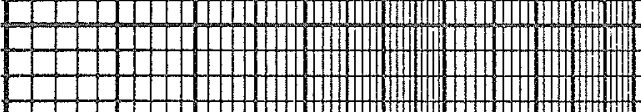

-

$+$

-

\begin{tabular}{l} 
(n) \\
\hline
\end{tabular}

Cldm

H17DTC

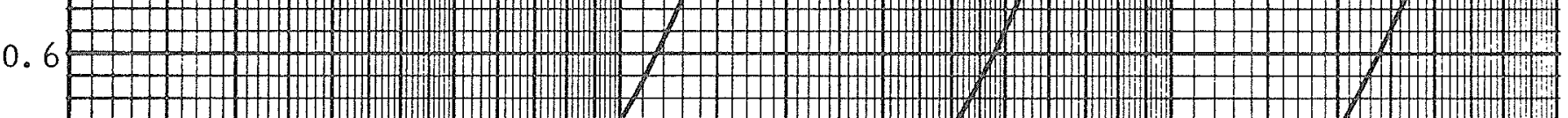

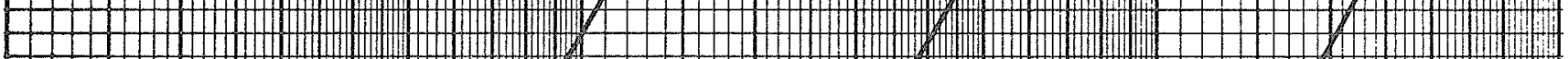
L1
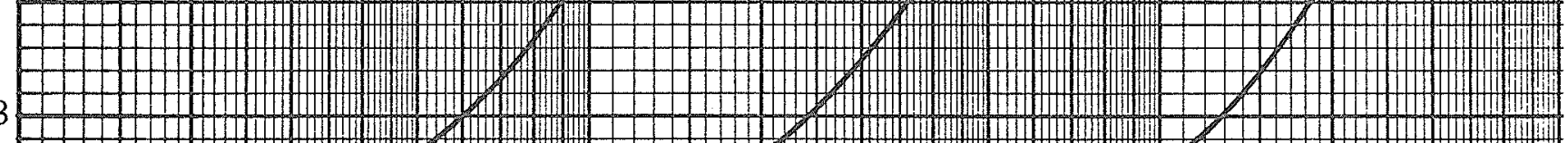

Fig. 3. General solution of the three-dimensional air-bubble plume for $G$ equal $0.25,1.00$ and 5.00. The nominal half-width $b=\left[\frac{\mathrm{g} \mathrm{q}_{\mathrm{O}} \mathrm{H}_{\mathrm{o}}}{\pi}\right]^{\frac{1}{2}}\left(1+\lambda^{2}\right)^{-1} \mathrm{u}_{\mathrm{b}}^{-3 / 2} \frac{\mathrm{w}}{\mathrm{v}}$. 
Numerical solutions to Eqs. (37) and (38) with Eqs. (39) and (40) to start the calculation were obtained using an IBM 360/75 digital computer with a subroutine "DEQ/ DIFFERENTIAL EQUATION SOLVER" in FOR TRAN IV (LEVEL G) language at the Booth Computing Center of California Institute of Technology. Figs. 2 and 3 show $\frac{\mathrm{v}^{2}}{\mathrm{w}}$ and $\frac{\mathrm{w}}{\mathrm{v}}$ plotted for values of $G$ of $0.25,1.0$ and 5.0 and $P$ equal to 0.20 . This is believed to cover most situations of practical interest. Small G values correspond to large flow rates of air, $\mathrm{q}_{\mathrm{O}}$, and small depths, $\mathrm{H}$.

It should be pointed out for the practical use of these graphs that the real source has to be virtually displaced a certain distance $\Delta \mathrm{x}$ which may be assumed to be about $0.8 \mathrm{~m}$.

\section{B. A Line Source in Homogeneous Ambient Fluid}

The two-dimensional air-bubble plume - the air-bubble curtain - may be generated by a row of closely spaced orifices. As to the analytical treatment, the basic assumptions and formulation of the problem are similar to the three-dimensional case and the governing equations consequently developed in the same manner.

$$
\begin{gathered}
u=u_{m} \cdot e^{-y^{2} / b^{2}} \\
\left(\rho_{a}-\rho_{m}\right)=\Delta \rho_{m} \cdot e^{-y^{2} /(\lambda b)^{2}}
\end{gathered}
$$

are the velocity and density profiles. The volume flux is written

$$
Q=\int_{-\infty}^{\infty} u d y=\sqrt{\pi} u_{m} b
$$

and continuity yields 


$$
\frac{d}{d x}\left(u_{m} b\right)=\frac{1}{\sqrt{\pi}} 2 \alpha u_{m}
$$

The buoyancy flux is given by

$$
B=\int_{-\infty}^{\infty}\left(u+u_{b}\right)\left(\rho_{a}-\rho_{m}\right) d y=\sqrt{\pi} u_{m} \Delta \rho_{m} \frac{\lambda b}{\sqrt{1+\lambda^{2}}}+\sqrt{\pi} u_{b} \Delta \rho_{m} \lambda b
$$

But

$$
B=q_{o}\left(\rho_{a}-\rho_{\text {air }}\right) \frac{H_{o}}{H_{0}+H-x} \approx \frac{q_{o} \rho_{a} H_{o}}{H_{0}+H-x}
$$

where $q_{0}=$ air discharge per unit length. This leads to the following buoyancy flux relation

$$
\sqrt{\pi} u_{m} \Delta \rho_{m} \frac{\lambda b}{\sqrt{1+\lambda^{2}}}+\sqrt{\pi} u_{b} \Delta \rho_{m} \lambda b=\frac{q_{o} \rho_{a} H_{o}}{H_{o}+H-x}
$$

Similarly, for the momentum flux an equation is written assuming $\rho_{\mathrm{m}} \approx \rho_{\mathrm{a}}$ (Boussinesq as sumption)

$$
\frac{d}{d x}\left(\frac{u_{m}^{2} b}{\sqrt{2}}\right)=\frac{\Delta \rho_{m}}{\rho_{a}} g \lambda b
$$

Eliminating $\frac{\Delta \rho_{\mathrm{m}}}{\rho_{\mathrm{a}}}$ from Eqs. (47) and (48) leads to the equations

$$
\begin{gathered}
\frac{d}{d x}\left(u_{m} b\right)=\frac{2}{\sqrt{\pi}} \alpha u_{m} \\
\frac{d}{d x}\left(u_{m}^{2} b\right)=\frac{\sqrt{2} g_{o} H_{o}}{\sqrt{\pi}\left(H_{0}+H-x\right)\left[\frac{u_{m}}{\sqrt{1+\lambda^{2}}}+u_{b}\right]}
\end{gathered}
$$


Eqs. (49) and (50) converge to the simple plume relation as $\mathrm{x} \rightarrow 0$ as $u_{m}>>u_{b}$ close to the source. Hence, the following simple plume relations will provide for the required starting conditions

$$
\begin{gathered}
\frac{d}{d x}\left(u_{m} b\right)=\frac{2}{\sqrt{\pi}} \alpha u_{m} \\
\frac{d}{d x}\left(u_{m}^{2} b\right)=\frac{\sqrt{2} q_{o} H_{o} \sqrt{1+\lambda^{2}}}{\sqrt{\pi}\left(H_{o}+H\right) u_{m}}
\end{gathered}
$$

Solving Eqs. (51) and (52) we arrive at

$$
\begin{gathered}
u_{m}=\left[\frac{g q_{0} H_{0} \sqrt{1+\lambda^{2}}}{\sqrt{2} \alpha\left(H_{0}+H\right)}\right]^{\frac{1}{3}} \\
b=\frac{2}{\sqrt{\pi}} \alpha x
\end{gathered}
$$

These equations are used to give the starting conditions for the numerical integration of Eqs. (49) and (50) reduced for quadrature

$$
\begin{aligned}
& \frac{d u_{m}}{d x}=-\frac{2 \alpha u_{m}}{\sqrt{\pi} b}+\frac{\sqrt{2} g q_{o} H_{o}}{\sqrt{\pi}\left[\frac{u}{\left(1+\lambda^{2}\right)^{\frac{1}{2}}}+u_{b}\right]\left(H_{o}+H-x\right) u_{m} b} \\
& \frac{d b}{d x}=\frac{4 \alpha}{\sqrt{\pi}}-\frac{\sqrt{2}}{\sqrt{\pi}} \frac{g q_{o} H_{o}}{\left[\frac{u_{m}}{\left.\left(1+\lambda^{2}\right)^{\frac{1}{2}}+u_{b}\right]\left(H_{o}+H-x\right) u_{m}^{2}}\right.}
\end{aligned}
$$


Normalized Equations

Following the same procedure as for the three-dimensional case we may write the differential equations in normalized form. With

$$
\begin{aligned}
& \mathrm{V}=\left(\frac{\sqrt{2^{g} \mathrm{q}_{\mathrm{o}} \mathrm{H}_{\mathrm{o}}}}{\sqrt{\pi}}\right) \cdot \mathrm{u}_{\mathrm{b}}^{-1} \cdot \mathrm{v}=\mathrm{u}_{\mathrm{m}}^{2} \cdot \mathrm{b} \\
& \mathrm{W}=\left(\frac{\sqrt{2} \mathrm{g \textrm {q } _ { \mathrm { O } } \mathrm { H } _ { \mathrm { o } }}}{\sqrt{\pi}}\right) \cdot\left(1+\lambda^{2}\right)^{-\frac{1}{2}} \cdot \mathrm{u}_{\mathrm{b}}^{-2} \mathrm{w}=\mathrm{u}_{\mathrm{m}} \cdot \mathrm{b} \\
& \mathrm{Z}=\frac{\mathrm{H}_{\mathrm{o}}+\mathrm{H}-\mathrm{x}}{\mathrm{H}_{\mathrm{O}}+\mathrm{H}}
\end{aligned}
$$

these equations are

$$
\begin{aligned}
\frac{d w}{d z} & =-G \frac{v}{w} \\
(v+w) \frac{d v}{d z} & =-\frac{w}{z}
\end{aligned}
$$

where as before $v$ and $w$ represent the dimensionless momentum and mass fluxes and $\mathrm{z}$ is a dimensionless length. The source parameter $G$ is defined by

$$
G=\sqrt{2}\left(H_{0}+H\right)\left(g_{0} H_{o}\right)^{-1} \alpha\left(1+\lambda^{2}\right) u_{b}^{3}
$$

Eqs. (58) and (59) have to be integrated from $z=1$ to $z=P=\frac{H_{0}}{H_{0}+H}$ for a given value of $\mathrm{G}$

$u_{m}, b$ and $x$ are determined by

$$
\begin{aligned}
& u_{m}=\left(1+\lambda^{2}\right)^{\frac{1}{2}} u_{b} \frac{v}{w} \\
& b=\frac{\sqrt{2} g_{0} H_{o}}{\sqrt{\pi}\left(1+\lambda^{2}\right) u_{b}^{3}} \frac{w^{2}}{v}
\end{aligned}
$$




$$
\begin{array}{r}
-20- \\
x=\left(H_{0}+H\right)(1-z)
\end{array}
$$

Similar to the three-dimensional case we assume that the airbubble equations converge to give the simple plume relations close to the source. This provides us with the following starting conditions for the integration of the normalized equations

$$
\begin{aligned}
& w=2^{1 / 6} G^{2 / 3}(1-z) \\
& v=2^{1 / 3} G^{1 / 3}(1-z)
\end{aligned}
$$

Figs. 4 and 5 show $\frac{\mathrm{V}}{\mathrm{W}}$ and $\frac{\mathrm{w}^{2}}{\mathrm{~V}}$ plotted for $\mathrm{G}$ values of $0.10,0.50$ and 1.50 and $P$ equal to 0.20 . As in the three-dimensional case we have, for the practical use of these graphs, to account for the effect of the virtual displacement of the source.

\section{A. A Point Source with Zero Slip Velocity.}

We can write the conservation equations for the three-dimensional air-bubble plume with zero slip velocity and then combine the momentum flux and buoyancy flux relations. This leads to the following governing equations.

$$
\begin{aligned}
& \frac{\mathrm{d}}{\mathrm{dx}}\left(u_{m} b^{2}\right)=2 \alpha u_{m} b \\
& \frac{d}{d x}\left(u_{m}^{2} b^{2}\right)=\frac{2 g_{0} H_{o}\left(1+\lambda^{2}\right)}{\pi\left(H_{o}+H-x\right) u_{m}}
\end{aligned}
$$

With

$$
\begin{aligned}
& \mathrm{V}=(2 \alpha)^{\frac{1}{3}}\left[\frac{2}{\sqrt{\pi}}\left(1+\lambda^{2}\right)\right]^{\frac{1}{3}}\left(\mathrm{~g} \mathrm{q}_{\mathrm{O}} \mathrm{H}_{\mathrm{o}}\right)^{\frac{1}{3}}\left(\mathrm{H}_{\mathrm{o}}+\mathrm{H}\right)^{\frac{1}{3}} \mathrm{v}=\mathrm{u}_{\mathrm{m}} \cdot \mathrm{b} \\
& \mathrm{W}=(2 \alpha)^{4 / 3}\left[\frac{2}{\sqrt{\pi}}\left(1+\lambda^{2}\right)\right]^{\frac{1}{2}}\left(\mathrm{~g} \mathrm{q}_{\mathrm{O}} \mathrm{H}_{\mathrm{O}}\right)^{\frac{1}{3}}\left(\mathrm{H}_{\mathrm{O}}+\mathrm{H}\right)^{4 / 3} \mathrm{w}=\mathrm{u}_{\mathrm{m}} \mathrm{b}^{2}
\end{aligned}
$$




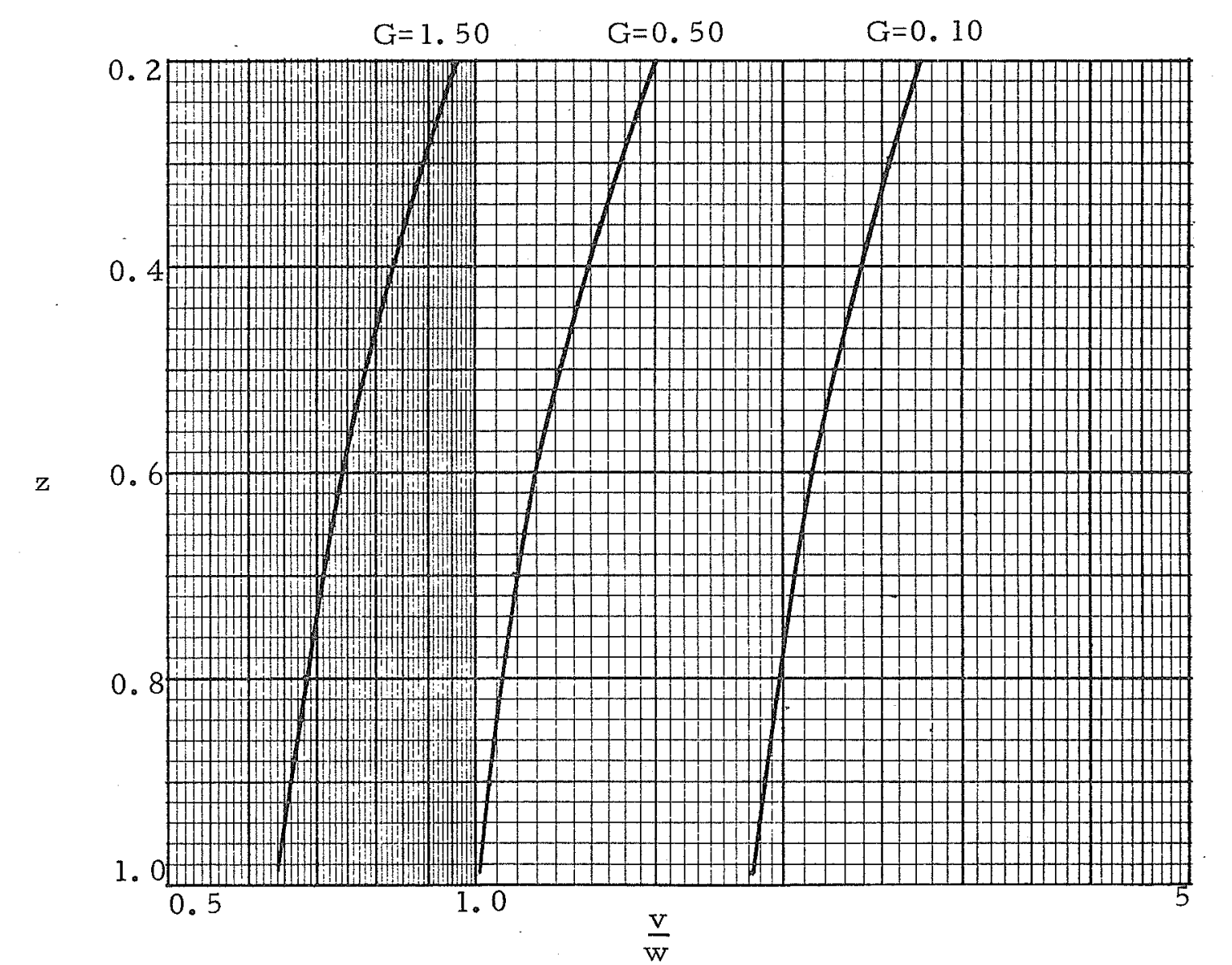

Fig. 4. General solution of the two-dimensional air-bubble plume for $G$ equal $0.10,0.50$ and 1.50 . The centerline velocity $u_{m}=\left(1+\lambda^{2}\right)^{\frac{1}{2}} u_{b} \frac{v}{w}$. 


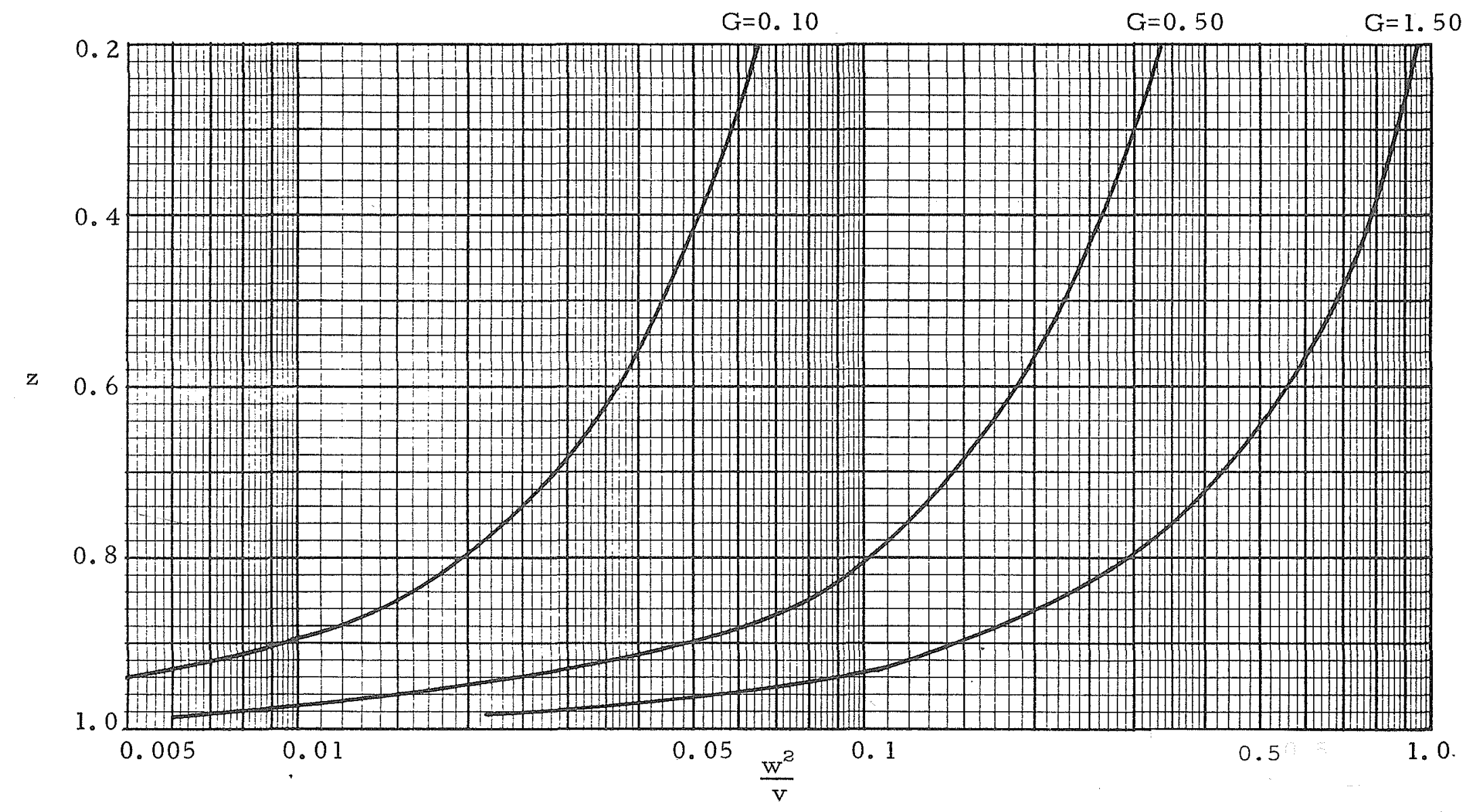

Fig. 5. General solution of the two-dimensional air-bubble plume for G equal $0.1,0.5$ and 1.5 . The nominal half-width $b=\frac{\sqrt{2} \mathrm{~g}_{\mathrm{o}} \mathrm{H}_{\mathrm{o}}}{\sqrt{\pi}\left(1+\lambda^{2}\right) \mathrm{u}_{\mathrm{b}}^{3}} \frac{\mathrm{w}^{2}}{\mathrm{v}}$. 


$$
z=\frac{H_{0}+H-x}{H_{0}+H}
$$

the normalized equations take the form

$$
\begin{aligned}
\frac{d w}{d z} & =-v \\
\frac{d v^{2}}{d z} & =-\frac{w}{z v^{2}}
\end{aligned}
$$

$\mathrm{u}_{\mathrm{m}}, \mathrm{b}$ and $\mathrm{x}$ are determined by

$$
\begin{aligned}
& \mathrm{u}_{\mathrm{m}}=\frac{\left(\mathrm{g}_{\mathrm{O}} \mathrm{H}_{\mathrm{o}}\right)^{\frac{1}{3}}\left(1+\lambda^{2}\right)^{\frac{1}{3}} \mathrm{v}^{2}}{(2 \pi)^{\frac{1}{3}} \alpha^{\frac{2}{3}}\left(\mathrm{H}_{\mathrm{o}}+\mathrm{H}\right)^{\frac{2}{3}} \frac{\mathrm{w}}{\mathrm{w}}} \\
& \mathrm{b}=2 \alpha\left(\mathrm{H}_{\mathrm{o}}+\mathrm{H}\right) \frac{\mathrm{w}}{\mathrm{v}} \\
& \mathrm{x}=\left(\mathrm{H}_{\mathrm{o}}+\mathrm{H}\right)(1-\mathrm{z})
\end{aligned}
$$

The normalized equations are solved numerically with the starting conditions derived from the simple plume relations in normalized form

$$
\begin{aligned}
& w=\frac{3}{5}\left(\frac{27}{60}\right)^{\frac{1}{3}}(1-z)^{5 / 3} \\
& v=\left(\frac{27}{60}\right)^{\frac{1}{3}}(1-z)^{\frac{2}{3}}
\end{aligned}
$$

Figs. 6 and 7 show the normalized solution of the threedimensional air-bubble plume with zero slip velocity. 


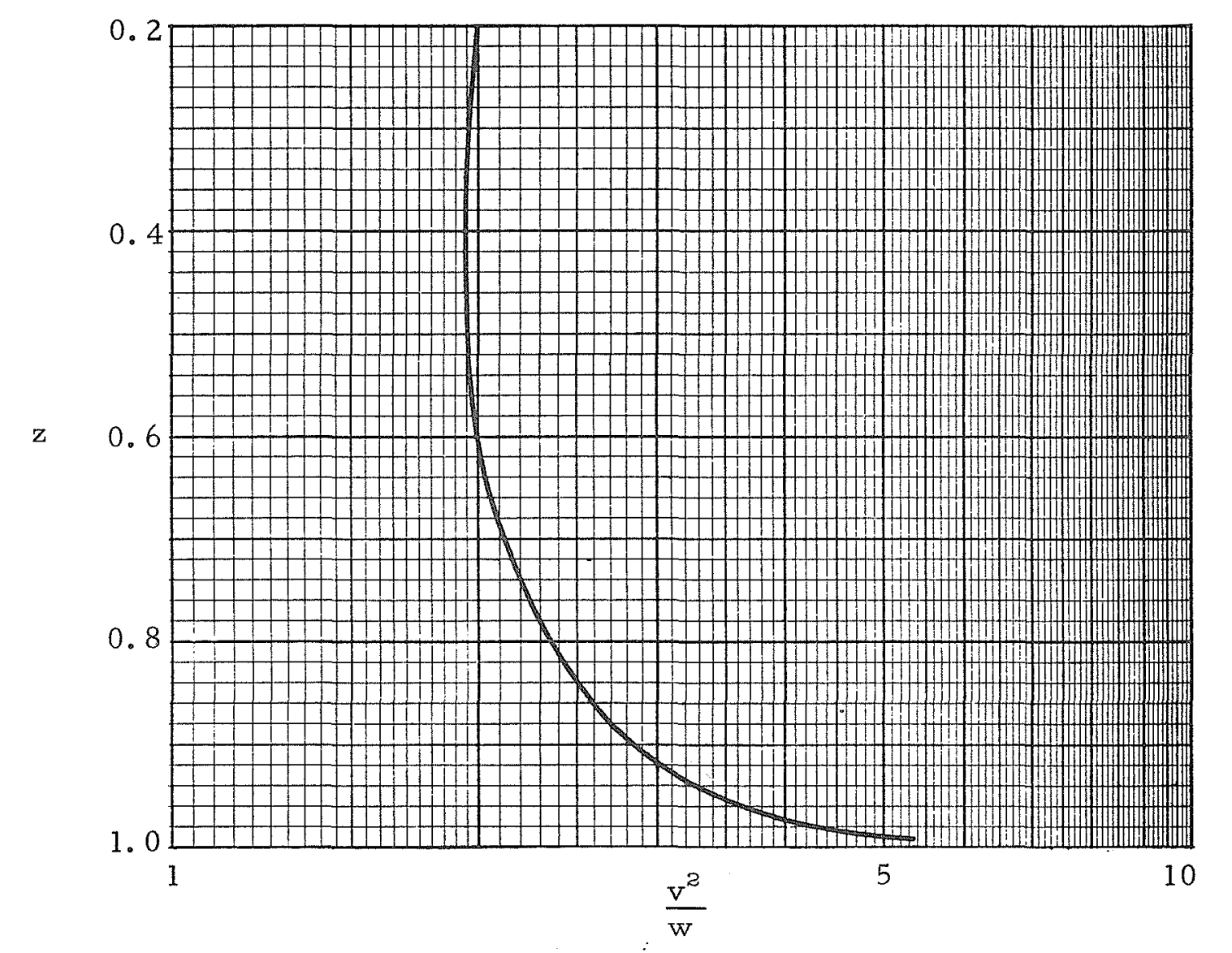

Fig. 6. General solution for the three-dimensional air-bubble plume with zero slif, velocity. The centerline velocity $u_{m}=\frac{\left(g_{0} H_{0}\right)^{\frac{3}{3}}\left(1+\lambda^{2}\right)^{\frac{3}{3}}}{(2 \pi)^{\frac{1}{3}} \alpha^{\frac{2}{3}}\left(H_{0}+H\right)^{\frac{\frac{z}{3}}{3}}} \frac{v^{2}}{w}$. 


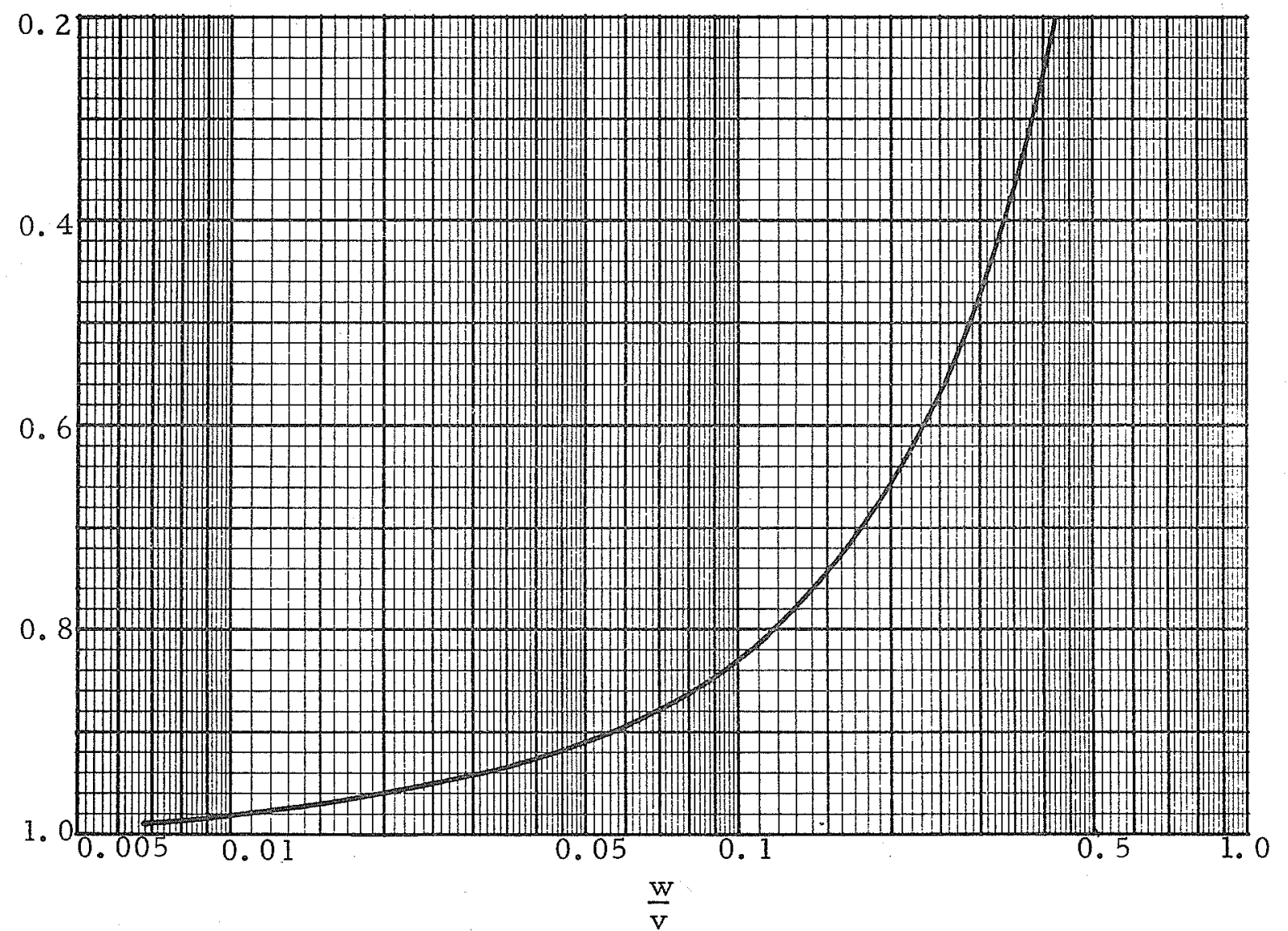

Fig. 7. General solution of the three-dimensional air-bubble plume with zero slip velocity. The nominal half-width $\mathrm{b}=2 \dot{\alpha}\left(\mathrm{H}_{\mathrm{o}}+\mathrm{H}\right) \frac{\mathrm{w}}{\mathrm{v}}$. 
2B. A Line Source with Zero Slip Velocity.

The governing equations are

$$
\begin{aligned}
& \frac{\mathrm{d}}{\mathrm{dx}}\left(\mathrm{u}_{\mathrm{m}} \mathrm{b}\right)=\frac{2}{\sqrt{\pi}} \alpha u_{\mathrm{m}} \\
& \frac{\mathrm{d}}{\mathrm{dx}}\left(\mathrm{u}_{\mathrm{m}}^{2} \mathrm{~b}\right)=\frac{\sqrt{2} \mathrm{~g} \mathrm{q}_{\mathrm{o}} \mathrm{H}_{\mathrm{o}}\left(1+\lambda^{2}\right)^{\frac{1}{2}}}{\sqrt{\pi}\left(\mathrm{H}_{\mathrm{o}}+\mathrm{H}-\mathrm{x}\right) \mathrm{u}_{\mathrm{m}}}
\end{aligned}
$$

With the following definitions

$$
\begin{aligned}
& \mathrm{V}=\left(\frac{2 \alpha}{\sqrt{\pi}}\right)^{\frac{1}{3}}\left(1+\lambda^{2}\right)^{\frac{1}{3}}\left(\frac{\sqrt{2}}{\sqrt{\pi}} g q_{0} H_{0}\right)^{\frac{2}{3}}\left(H_{0}+H\right)^{\frac{1}{3}} v=u_{m}^{2} b \\
& W=\left(\frac{2 \alpha}{\sqrt{\pi}}\right)^{\frac{2}{3}}\left(1+\lambda^{2}\right)^{1 / 6}\left(\frac{\sqrt{2}}{\sqrt{\pi}} g q_{0} H_{0}\right)^{\frac{1}{3}}\left(H_{0}+H\right)^{\frac{2}{3}} w=u_{m} \cdot b \\
& z=\frac{H_{0}+H-x}{H_{0}+H}
\end{aligned}
$$

the normalized equations may be written

$$
\begin{aligned}
& \frac{d w}{d z}=-\frac{v}{w} \\
& \frac{d v}{d z}=-\frac{w}{z v}
\end{aligned}
$$

$u_{m}, b$ and $x$ are given by

$$
\begin{aligned}
u_{m} & =\frac{\left(g q_{0} H_{0}\right)^{\frac{1}{3}}\left(1+\lambda^{2}\right)^{1 / 6}}{(\sqrt{2} \alpha)^{\frac{1}{3}}\left(H_{0}+H\right)^{\frac{1}{3}}} \frac{v}{w} \\
b & =\frac{2}{\sqrt{\pi}} \alpha\left(H_{0}+H\right) \frac{w^{2}}{v} \\
x & =\left(H_{0}+H\right)(1-z)
\end{aligned}
$$




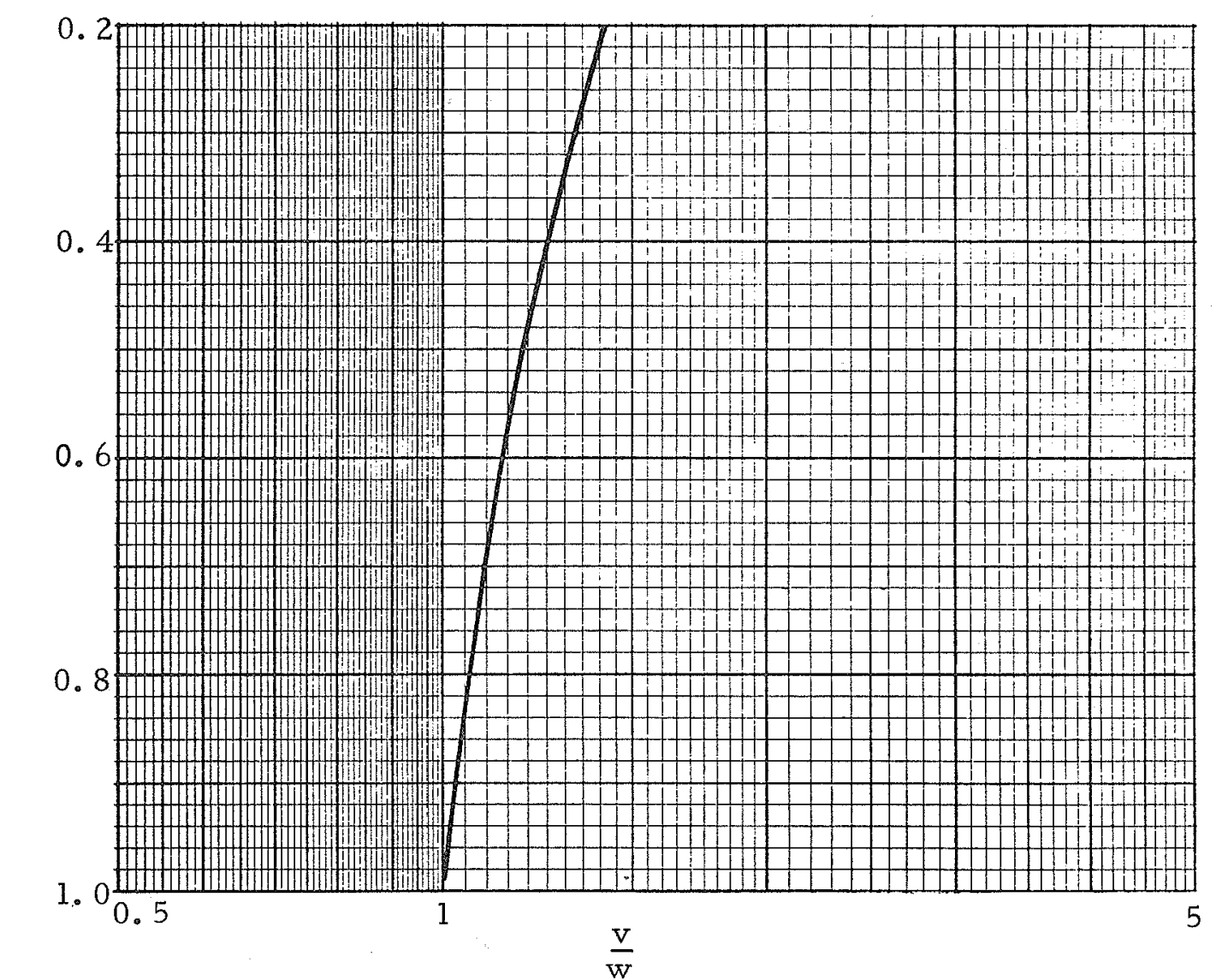

Fig. 8. General solution of the two-dimensional air-bubble plume with zero slip velocity. The centerline velocity

$$
u_{m}=\frac{\left(g_{o} H_{o}\right)^{\frac{1}{3}}\left(1+\lambda^{2}\right)^{1 / 6}}{(\sqrt{2} \alpha)^{\frac{1}{3}}\left(H_{O}+H\right)^{\frac{1}{3}}} \frac{\mathrm{v}}{w} .
$$


z

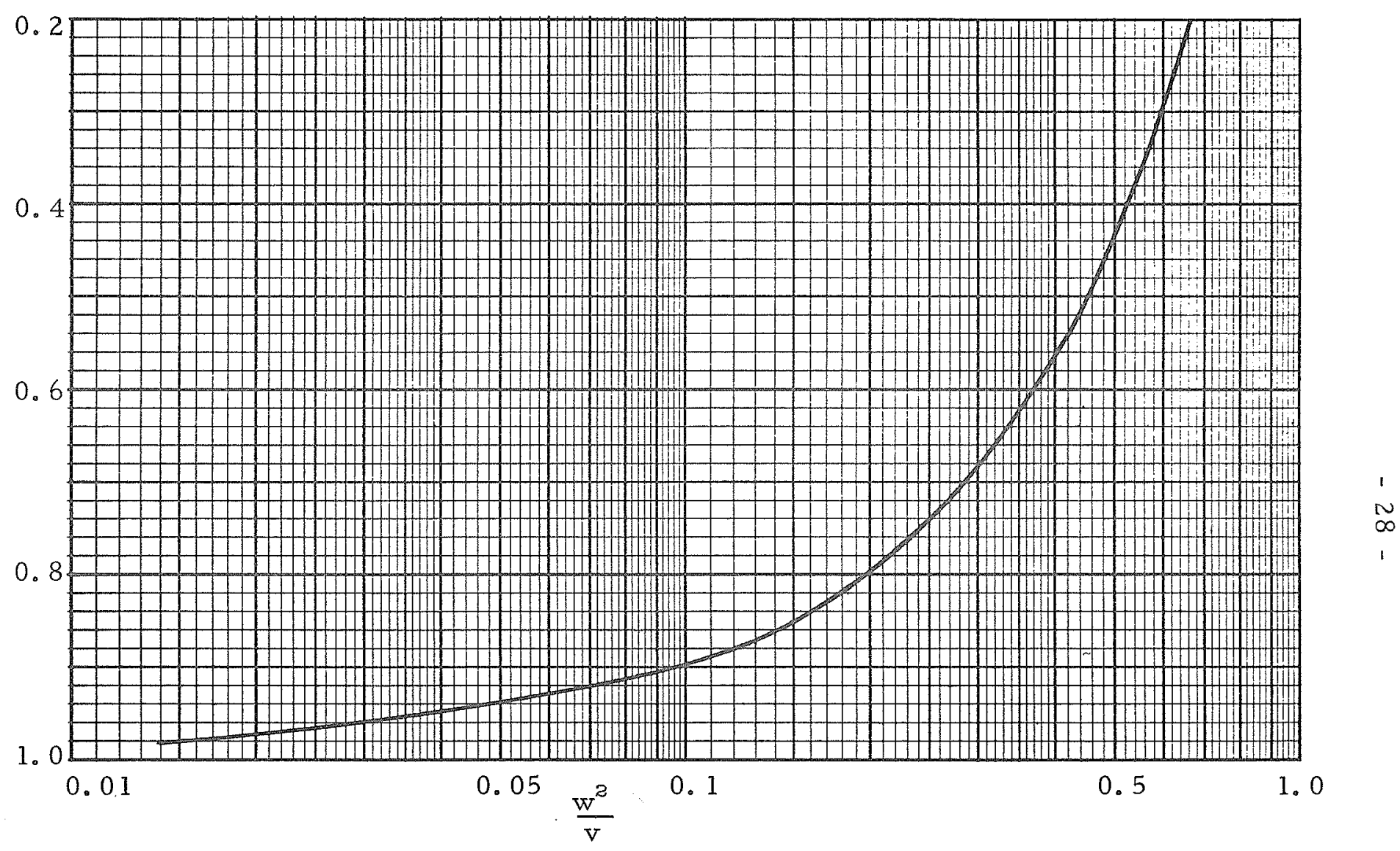

Fig. 9. General solution of the two-dimensional air-bubble plume with zero slip velocity. The nominal half-width

$$
\mathrm{b}=\frac{2}{\sqrt{\pi}} \alpha\left(\mathrm{H}_{\mathrm{O}}+\mathrm{H}\right) \frac{\mathrm{w}^{2}}{\mathrm{v}}
$$


There is no analytical solution to Eqs. (75) and (76) in closed form which takes the boundary cunditions $v=w=0$ for $z=1$. Starting conditions for the numerical integration are provided for by the simple plume relations in normalized form

$$
\begin{aligned}
& w=2^{1 / 6}(1-z) \\
& v=2^{1 / 3}(1-z)
\end{aligned}
$$

Eqs. (75) and (76) may now be integrated from $z=1$ to $z=P=\frac{H_{0}}{H_{0}+H}$. Figs. 8 and 9 show the normalized solution of the two-dimensional airbubble plume with zero slip velocity.

\section{NEGLECTING THE EFFECT OF COMPRESSIBILITY}

For the sake of completeness, let us also discuss a situation where the lighter fluid released from the source has no compressibility. If the two fluids are immiscible, bubbles will be produced at the source just as in the air-bubble case. The governing equations for a point source of buoyancy only are then with the source strength $\mathrm{q}_{\mathrm{O}} \mathrm{H}_{\mathrm{O}} /\left(\mathrm{H}_{\mathrm{O}}+\mathrm{H}\right)$

$$
\begin{aligned}
& \frac{d}{d x}\left(u_{m} b^{2}\right)=2 \alpha u_{m} b \\
& \frac{d}{d x}\left(u_{m}^{2} b^{2}\right)=\frac{2 g q_{0} H_{o}}{\pi\left(H_{o}+H\right)\left(\frac{u_{m}}{1+\lambda^{2}}+u_{b}\right)}
\end{aligned}
$$

Following the same normalization procedure as before we have

$$
\begin{aligned}
& \mathrm{V}=(2 \alpha)^{-1}\left(1+\lambda^{2}\right)^{-1} \mathrm{u}_{\mathrm{b}}^{-2}\left[\frac{2 \mathrm{~g} \mathrm{q}_{\mathrm{O}} \mathrm{H}_{\mathrm{o}}}{\pi\left(\mathrm{H}_{\mathrm{o}}+\mathrm{H}\right)}\right] \mathrm{v}=\mathrm{u}_{\mathrm{m}} \mathrm{b} \\
& \mathrm{W}=(2 \alpha)^{-2}\left(1+\lambda^{2}\right)^{-3} \mathrm{u}_{\mathrm{b}}^{-5}\left[\frac{2 \mathrm{gq_{ \textrm {o } } \mathrm { H } _ { \mathrm { o } }}}{\pi\left(\mathrm{H}_{\mathrm{o}}+\mathrm{H}\right)}\right]^{2} \mathrm{w}=\mathrm{u}_{\mathrm{m}} \mathrm{b}^{2}
\end{aligned}
$$




$$
x=(2 \alpha)^{-2}\left(1+\lambda^{2}\right)^{-2} u_{b}^{-3}\left[\frac{2 g q_{o} H_{o}}{\pi\left(H_{0}+H\right)}\right] z
$$

and the differential equations

$$
\begin{aligned}
\frac{d w}{d z} & =v \\
\left(v^{2}+w\right) \frac{d v^{2}}{d z} & =w
\end{aligned}
$$

As there is no analytical solution in closed form to Eqs. (83) and (84) that takes the boundary conditions $\mathrm{v}=\mathrm{w}=0$ at $\mathrm{z}=0$, the equations have to be solved numerically. The starting conditions are obtained from the simple plume relations

$$
\begin{aligned}
& v=\left(\frac{27}{60}\right)^{\frac{1}{3}} z^{\frac{2}{3}} \\
& w=\frac{3}{5}\left(\frac{27}{60}\right)^{\frac{1}{3}} z^{5 / 3}
\end{aligned}
$$

The solution is not given here. The two-dimensional case may be treated similarly.

\section{Example}

To exemplify the use of the present theory, take the case of a point source in homogeneous water with the following characteristical data

$$
\begin{aligned}
\mathrm{q}_{\mathrm{O}} & =4 \cdot 10^{-3} \mathrm{~m}^{3} / \mathrm{s} \\
\mathrm{H} & =10 \mathrm{~m} \\
\mathrm{H}_{\mathrm{O}} & =10.4 \mathrm{~m}
\end{aligned}
$$

We want to know the centerline velocity, $u_{m}$, the nominal half-width, $b$, and the generated vertical flow, $Q$, at say $5 \mathrm{~m}$ above the source. 
Let us assume the following values of $\lambda, \alpha$ and $u_{b}$

$$
\begin{aligned}
\lambda & =0.2 \\
\alpha & =0.07 \quad \text { (See Fig. 17) } \\
u_{b} & =0.30 \mathrm{~m} / \mathrm{s}
\end{aligned}
$$

The source parameter G, defined by Eq. (33), then takes the value $G=0.68$ and the normalized height above the mathematical origin, Eq. (32), is $z=\frac{20.4-5}{20.4+0.8}=0.73$ Figs. 2 and 3 give $\frac{v^{2}}{w}=1.80$ and $\frac{\mathrm{w}}{\mathrm{v}}=0.25$. $\mathrm{u}_{\mathrm{m}}$ and $\mathrm{b}$ then follow from Eqs. (36) and $Q=\pi u_{m} b^{2} \operatorname{can}$ be calculated. 


\section{COMPARISON WITH EXPERIMENTAL DATA}

Table 1 sums up the air-bubble plume cases that have been analyzed. To verify the theory and to determine the proper choice of values of the constants included in the theory - primarily the entrainment coefficient $\alpha$ and the spreading ratio $\lambda$ - the analytical results are compared with experimental data. Many experimental studies of air-bubble systems reported in the literature are not very comprehensive or consistent. A laboratory study of large scale airbubble plumes by Kobus (1968) covers both the two- and three-dimensional cases. The present theory is compared with the results given by Kobus.

Typical measurements of the centerline velocity and the lateral velocity distribution from two different experiments with a point source are plotted together with the theory in Figs. 10 to 12. For the theoretical calculations $\alpha$ values were chosen to give the best fit between observed and predicted rate of growth of the nominal plume half-width. The lateral spreading of the air-bubbles is slow relative to the expansion of the plume. Hence, the spreading ratio $\lambda$ is considerably less than one. Laboratory observations indicate that $\lambda$ is fairly constant throughout the rise of the plume, the order of magnitude about 0.2. Since theoretical calculations based on $\lambda=0.1,0.2$ or 0.3 give practically the same result we have used a constant value 0.2 in this study. For reasons that we will discuss later, the slip velocity, $u_{b}$, was also held constant and equal to $0.30 \mathrm{~m} / \mathrm{s}$ when comparing theoretical and experimental results for the three-dimensional air-bubble plumes. The experimental data

\footnotetext{
* Photographical recordings of air-bubble plumes. The experiments were conducted at Chalmers Institute of Technology.
} 
Table 1. Air-Bubble Plumes in Homogeneous Environment

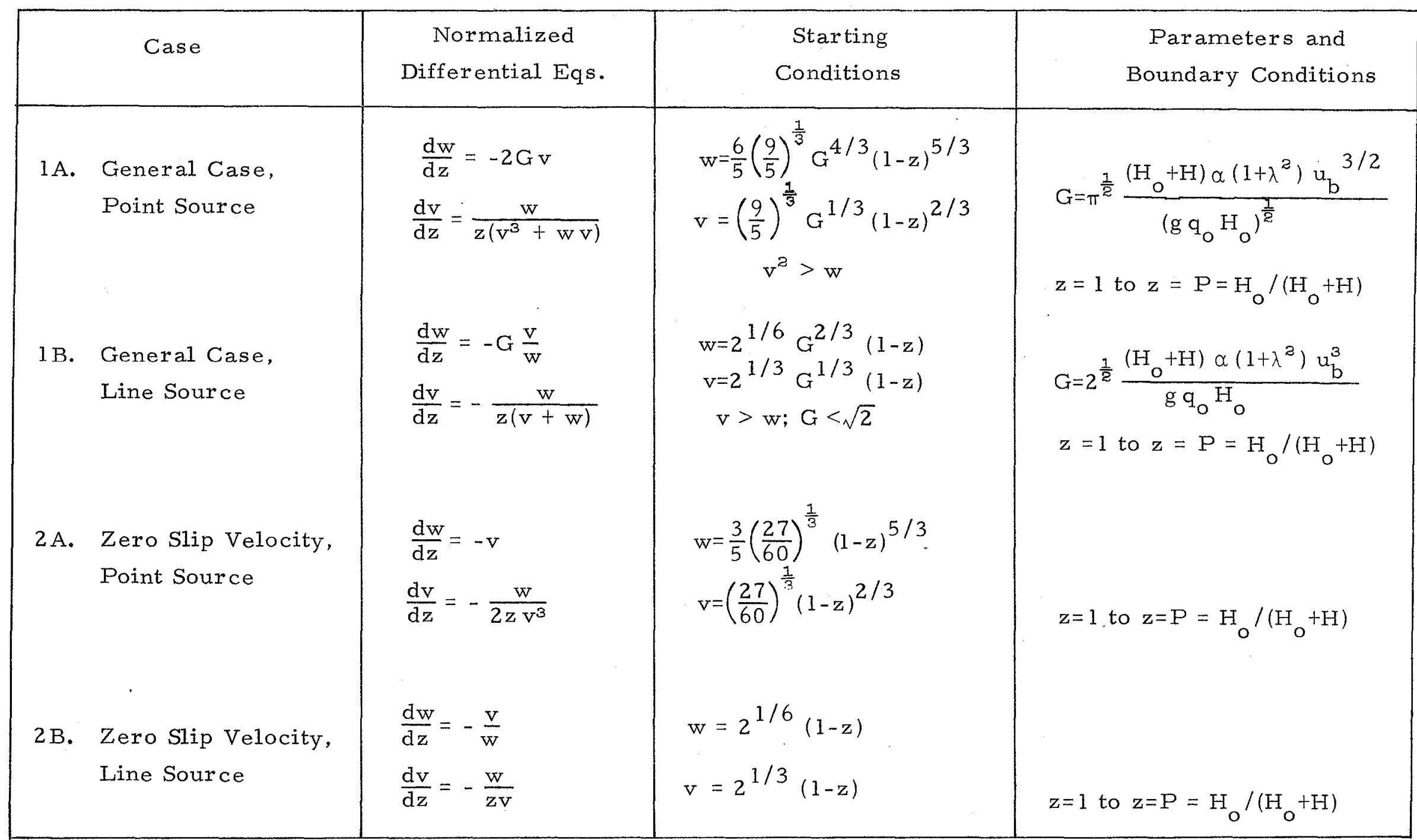




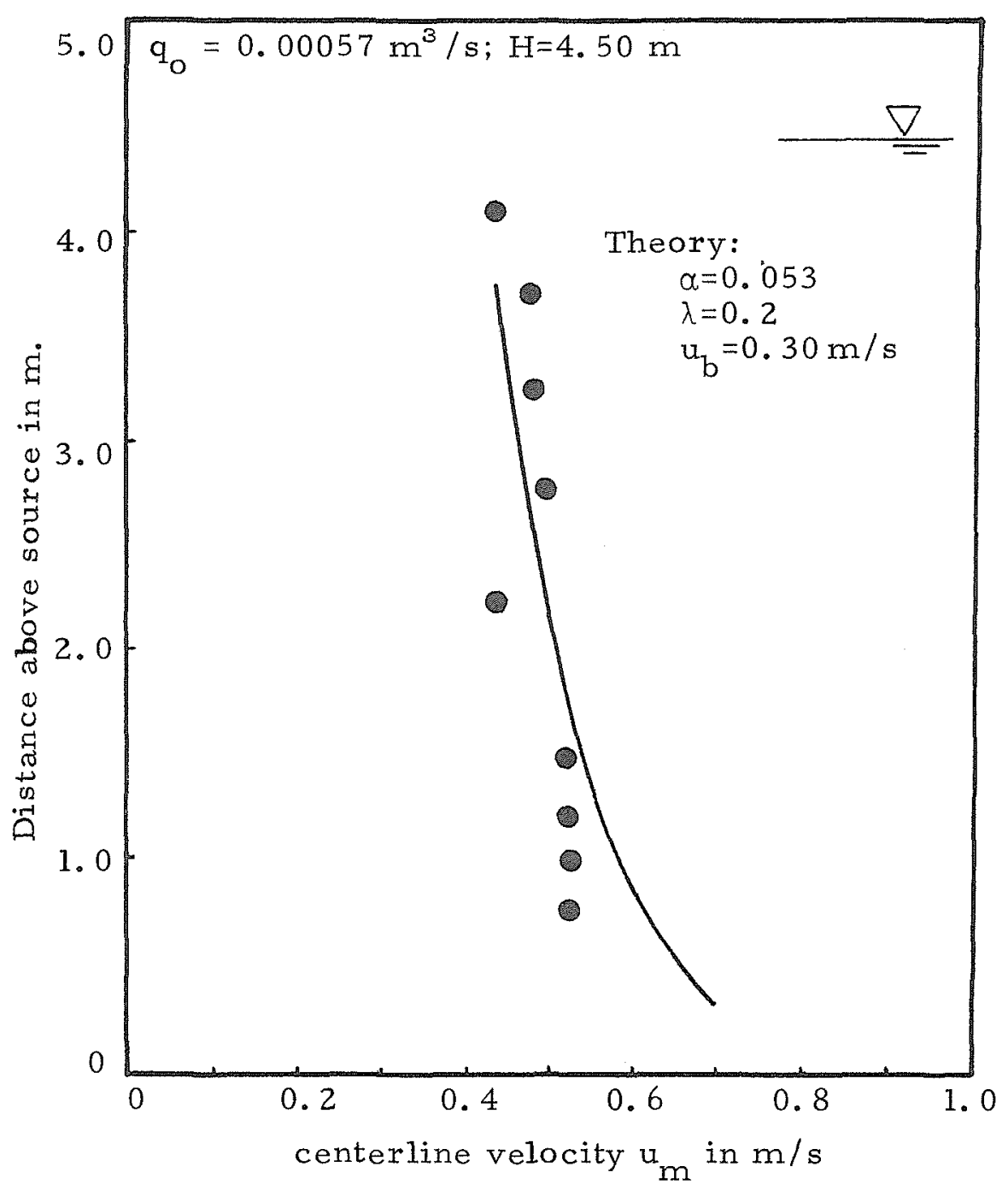

Fig. 10. Observed and predicted variation of centerline velocity with distance above the (real) source. Experimental data given by Kobus (1968). 


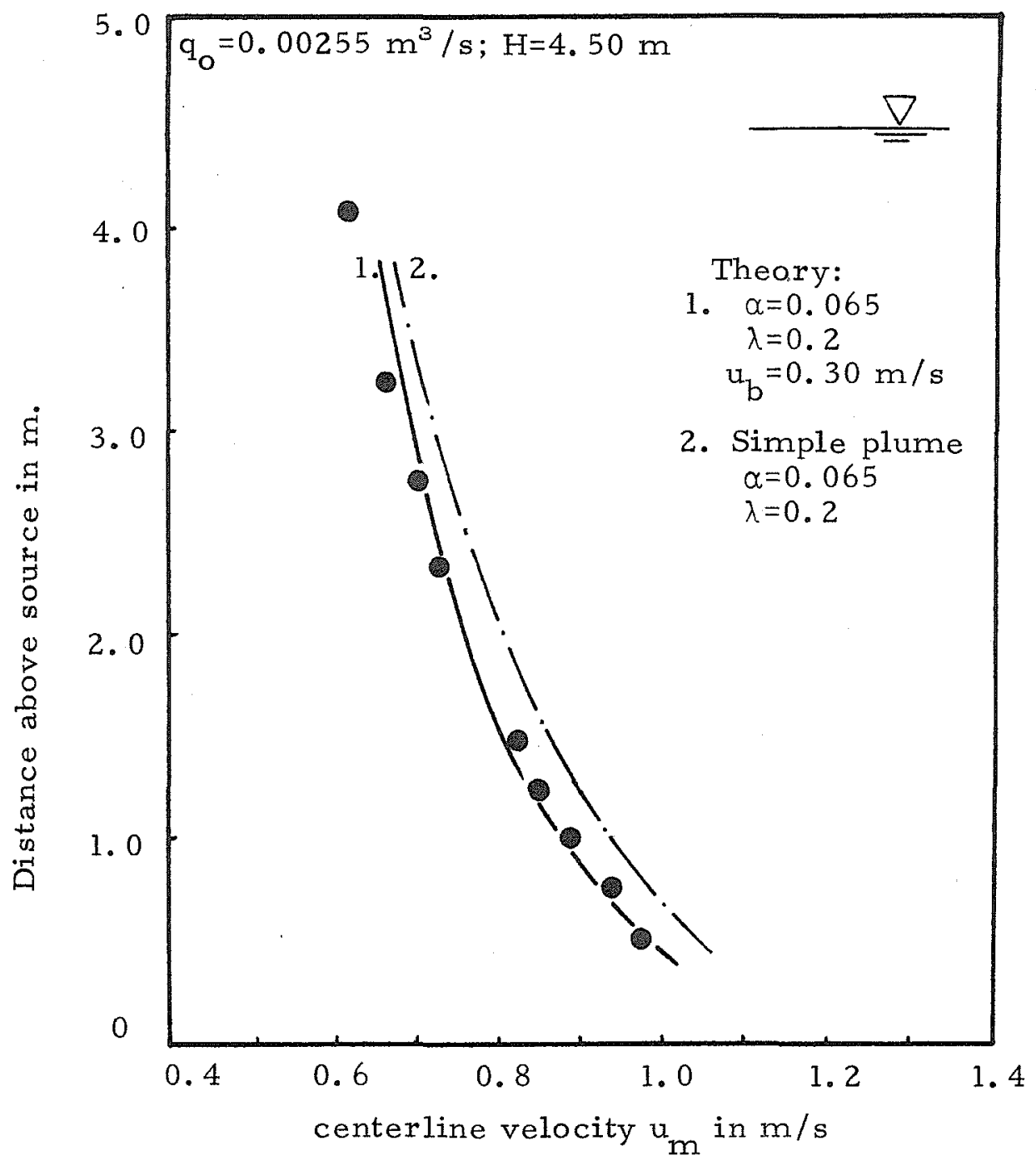

Fig. 11. Observed and predicted variation of centerline velocity with distance above the (real) source. Experimental data given by Kobus (1968). 


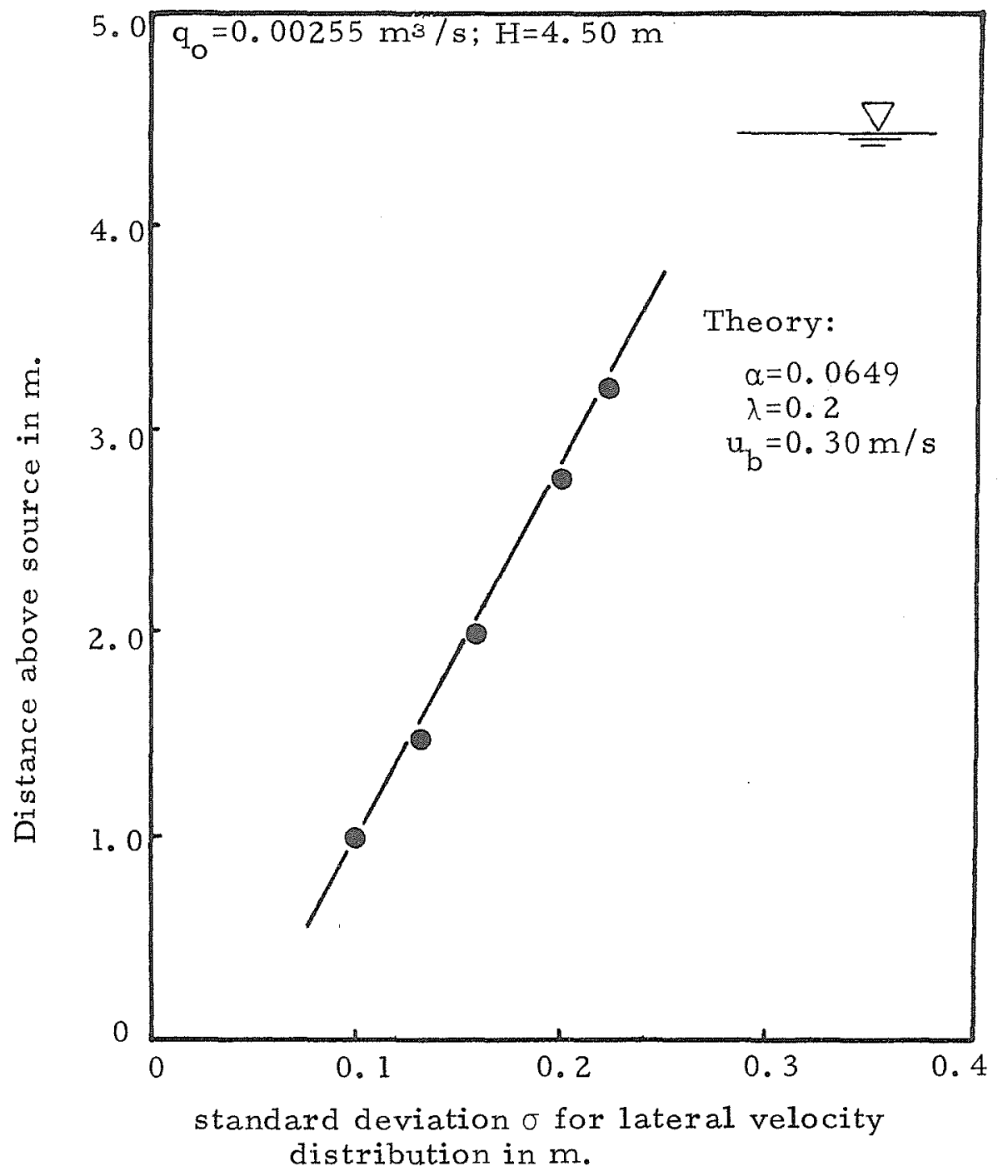

Fig. 12. Observed and predicted rate of growth of the lateral velocity profile with the distance above the (real) source. Experimental data by Kobus (1968). 
provide a strong support for the present theoretical approach as demonstrated by the two test runs in Figs. 10 to 12 .

Measured centerline velocities of air-bubble plumes from a single point source show little scattering and seem to be consistent. It is unfortunately difficult to get reliable data when conducting similar tests with air-bubble screens. One of the reasons for this is the fact that slow internal seiches tend to develop in the laboratory tank induced by the air-bubble system itself. Kobus has reported integration over periods as long as 5 minutes which of course tends to reduce the measured velocities if the air-bubble plume is oscillating. Figs. 13 to 16 show results from experiments with air-bubble curtains. Observed values of the centerline velocity seem to be somewhat lower than predicted velocities. This, however, can be reduced to a problem of curve fitting since the characteristic properties of the two-dimensional air-bubble plume expressed by the theory is supported by the experimental data just as in the three-dimensional case.

Measured centerline velocities are compared to the theory using three sets of different values of $\alpha, \lambda$ and $u_{b}$. The first calculation has $\lambda=0.2, u_{b}=0.30 \mathrm{~m} / \mathrm{s}$ and a value of $\alpha$ that makes the predicted expansion of the plume agree with the observed plume growth. For the second calculation $u_{b}$ was estimated as the difference between the rise velocity of the air-bubbles - also measured by Kobus - and the observed centerline velocity of the plume water as these two velocities are relatively constant. We have finally increased the $\alpha$ value to 0.16 in 


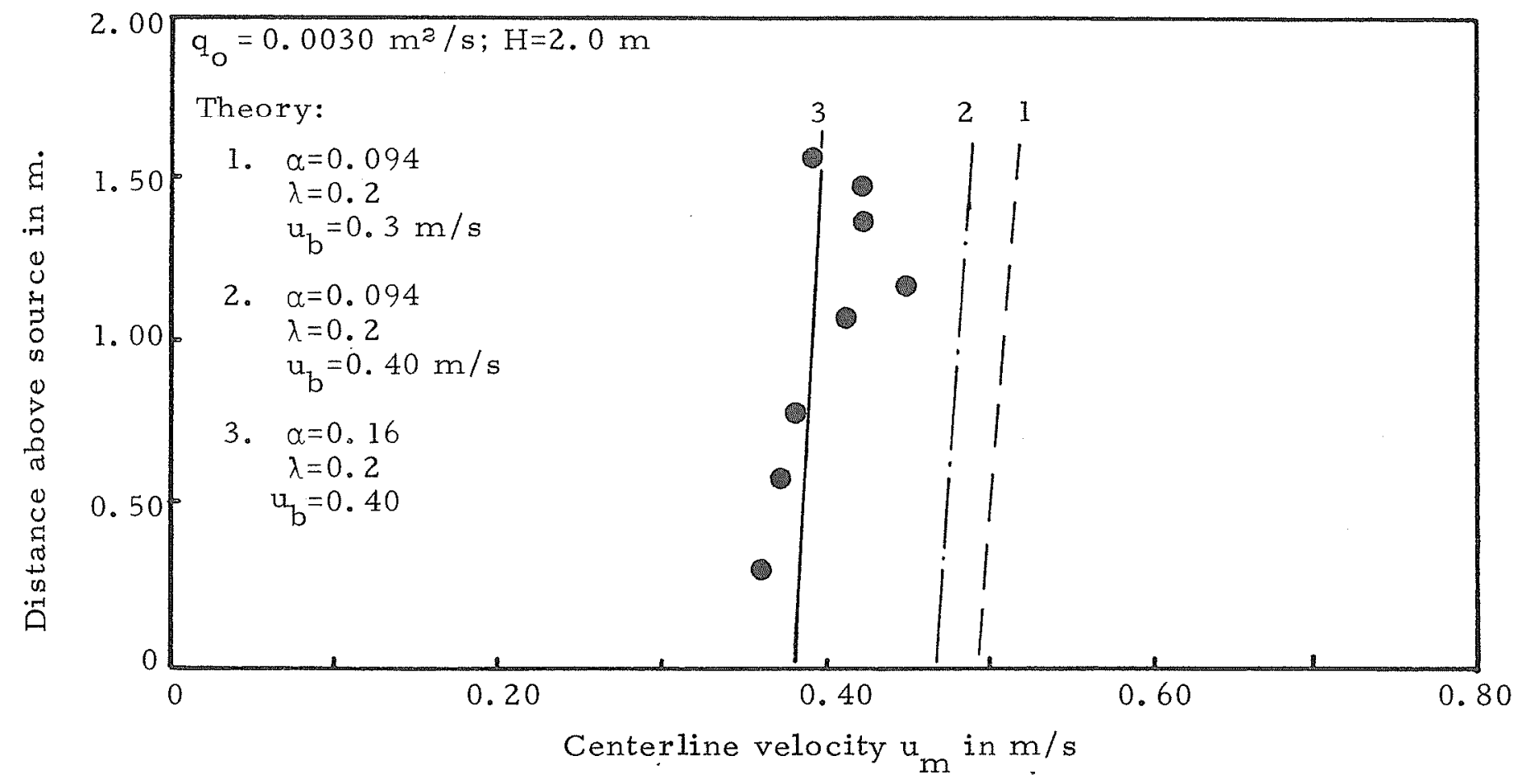

Fig. 13 Observed and predicted variation of centerline velocity with distance above the (real) source. Experimental data given by Kobus (1968). 


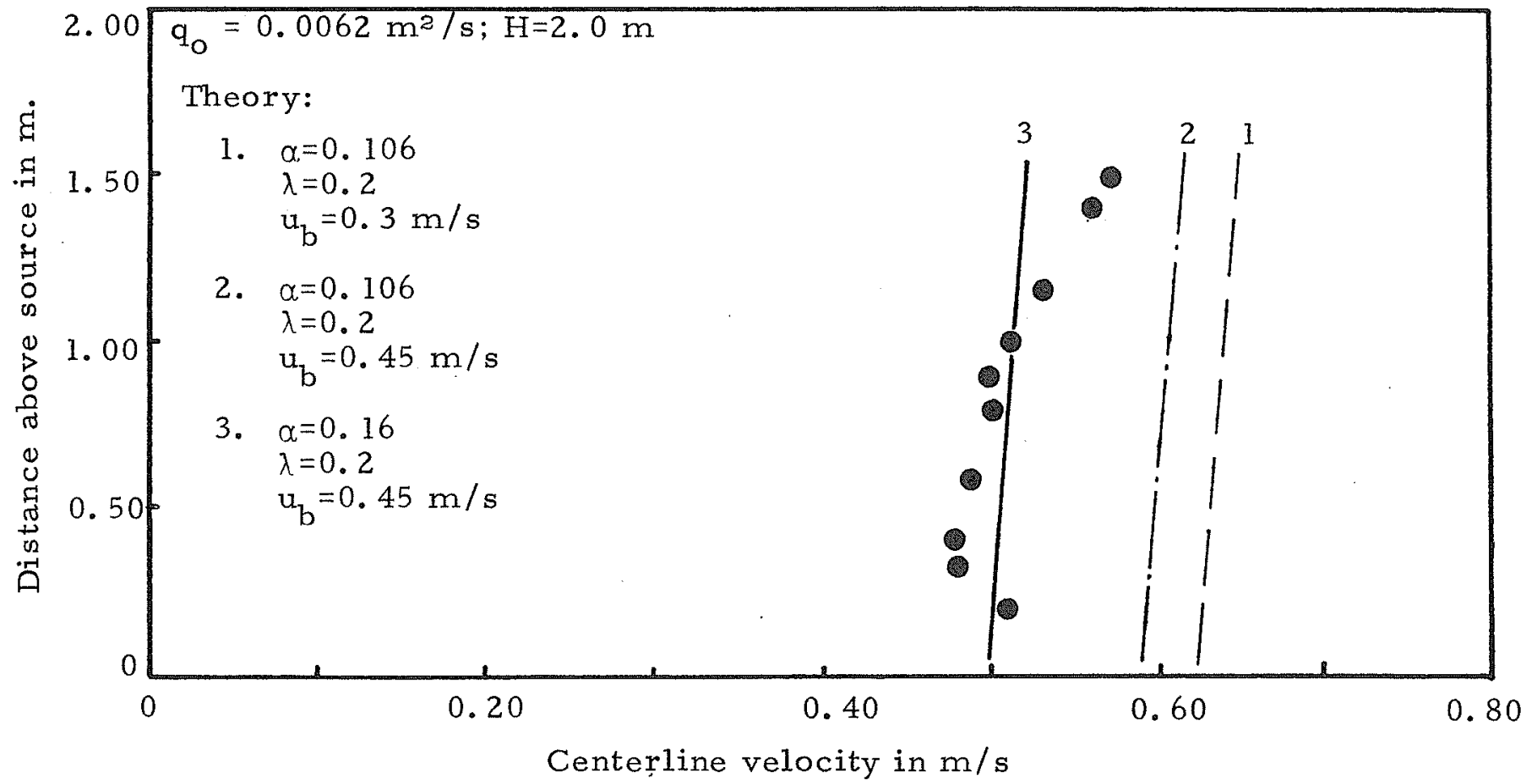

Fig. 14 Observed and predicted variation of centerline velocity with distance above the (real) source. Experimental data given by Kobus (1968). 


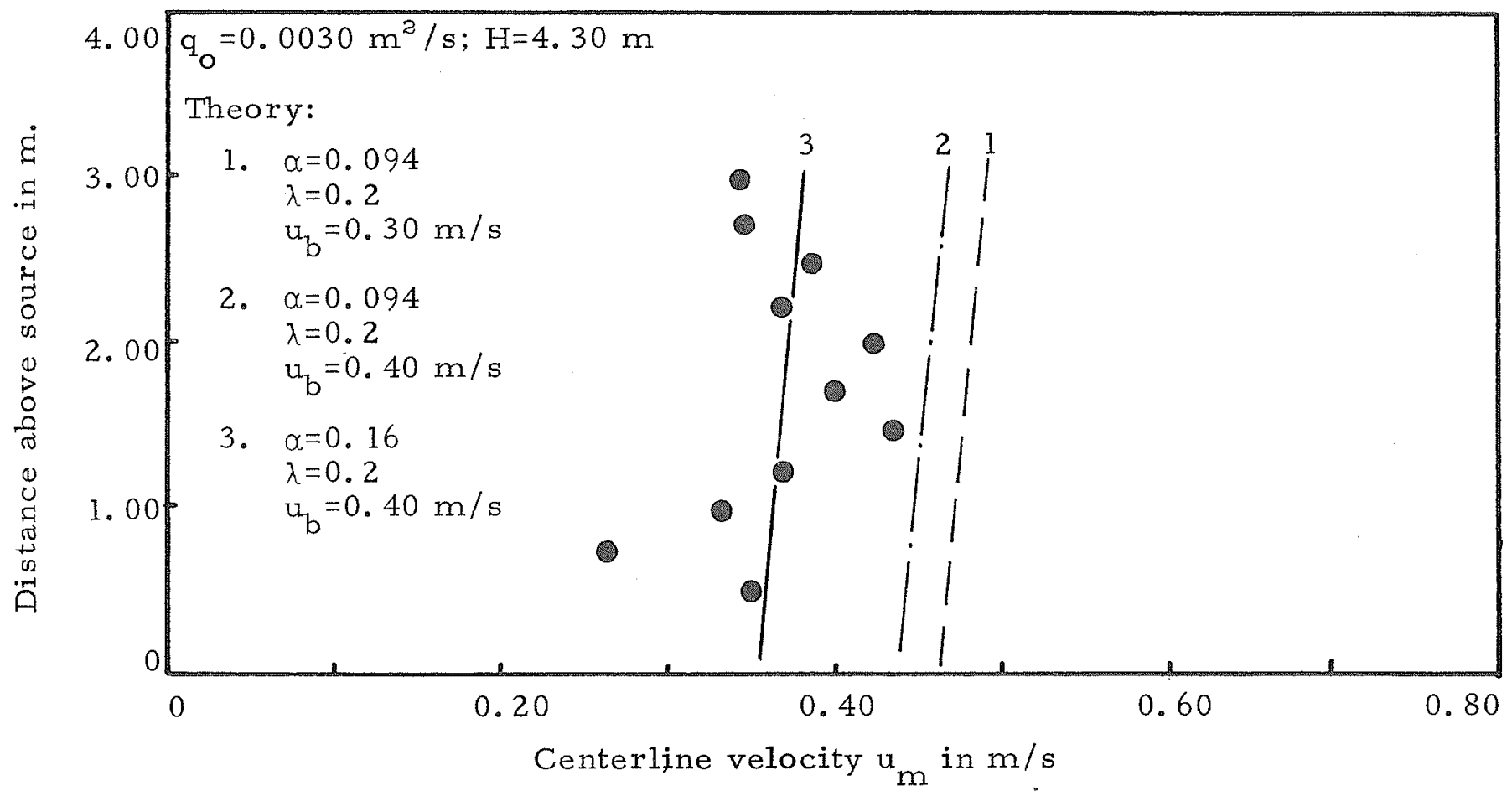

Fig. 15 Observed and predicted variation of centerline velocity with distance above the (real) source. Experimental data by Kobus (1968). 


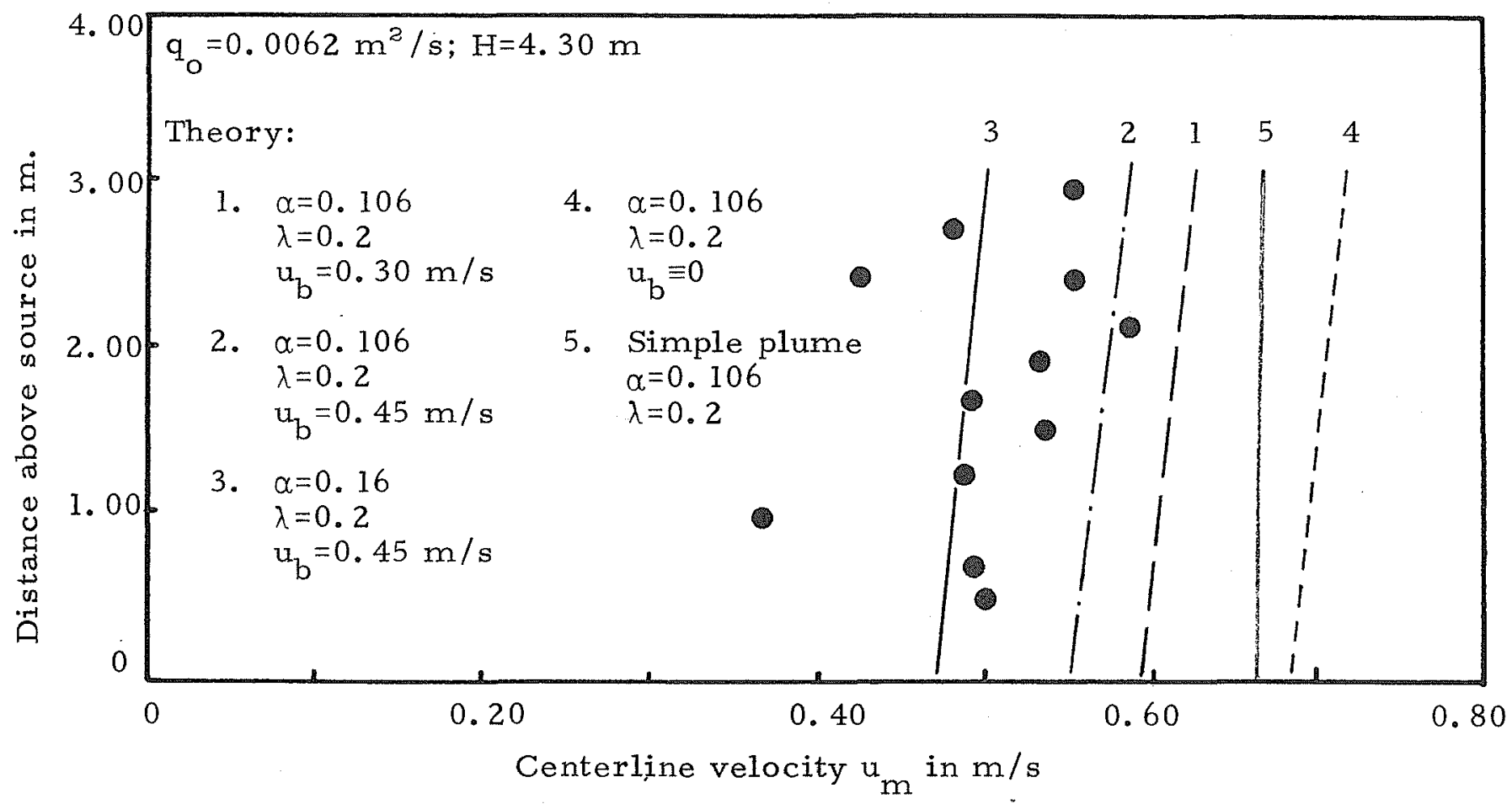

Fig. 16 Observed and predicted variation of centerline velocity with distance above the (real) source. Experimental data by Kobus (1968). 
-which case the observed and predicted velocities match each other very well but not the variation of the nominal plume half-width. Fig. 16 also shows the centerline velocity assuming a simple plume - no compressibility and no slip velocity - and the velocity in the case of zero slip velocity but with compressibility - small bubbles. Before making any conclusions we would first like to review some empirical background for the proper choice of values of the constants included in the theory.

It has been proved experimentally by Kobus that the rate of plume expansion characterized by $\frac{d b}{d x}$ is practically a constant, slightly a function of the rate of air flow, $q_{0}$, but independent of the source diameter in the range crvered by the experiments, that is from $0.05 \mathrm{~mm}$ to $0.5 \mathrm{~mm}$. The theoretical calculations reveal that $\mathrm{b}$ is essentially a function of $\alpha$ only. This means that a good estimate of the $\alpha$ value is

$$
\alpha=\frac{5}{6} \frac{\mathrm{db}}{\mathrm{dx}}=\frac{5 \sqrt{2}}{6} \frac{\mathrm{d} \sigma}{\mathrm{dx}}
$$

for the three-dimensional case and

$$
\alpha=\frac{\sqrt{\pi}}{2} \frac{\mathrm{db}}{\mathrm{dx}}=\frac{\sqrt{\pi}}{\sqrt{2}} \frac{\mathrm{d} \sigma}{\mathrm{dx}}
$$

for the two-dimensional case. Hence using the data given by Kobus we can plot $\alpha$ as a function of $q_{0}$, see Fig. 17 .

The $\alpha$-values for the case of a point source indicate a growth with the air flow rate reaching asymptotically a value of about 0.08 . It is of interest to note that Rouse, Yih and Humphreys (1952) found $\alpha=0.082$ for the case of a three-dimensional simple plume. Furthermore, experimental data by Lee and Emmons (1961) suggest an $\alpha$-value of 
about 0.16 for a buoyant line source. Although the air curtain experiments reported by Kobus only cover a relatively narrow range in $q_{0}$, it is possible that there is an increase of the $\alpha$-value with $q_{0}$, very similar to the three-dimensional case, with $\alpha$ reaching an asymptotic value of about 0.16 for very large air flow rates.

Studies on the rise velocity of single air-bubbles in still water show that there is a wide range in bubble sizes that have terminal velocities of the order of $0.3 \mathrm{~m} / \mathrm{s}$, see for instance Haberman and Morton (1954). Hence, it is believed that $\mathrm{u}_{\mathrm{b}}=0.30 \mathrm{~m} / \mathrm{s}$ is a proper value to use in most practical situations unless the discharge $r$ ate per orifice is exceptionally small as for instance in the case of a porous hose. As demonstrated by line 4 in Fig. 16 the buoyancy flux is more effectively used for generating a plume when the bubbles are small. Hence, the porous hose or a similar device producing very small airbubbles, represent the ideal design of an air-bubble system.

To summarize we have found that the experimental data support the proposed theory and there is a very good agreement between theory and observations in the three-dimensional case if proper values of the coefficients are used. In the two-dimensional case we have to choose large values of either the slip velocity or the entrainment coefficient to match theory and experiments. We are inclined to believe that the reason for this is measuring difficulties in the case of the air-bubble screen resulting in too low values of the observed centerline velocities reported by Kobus. 


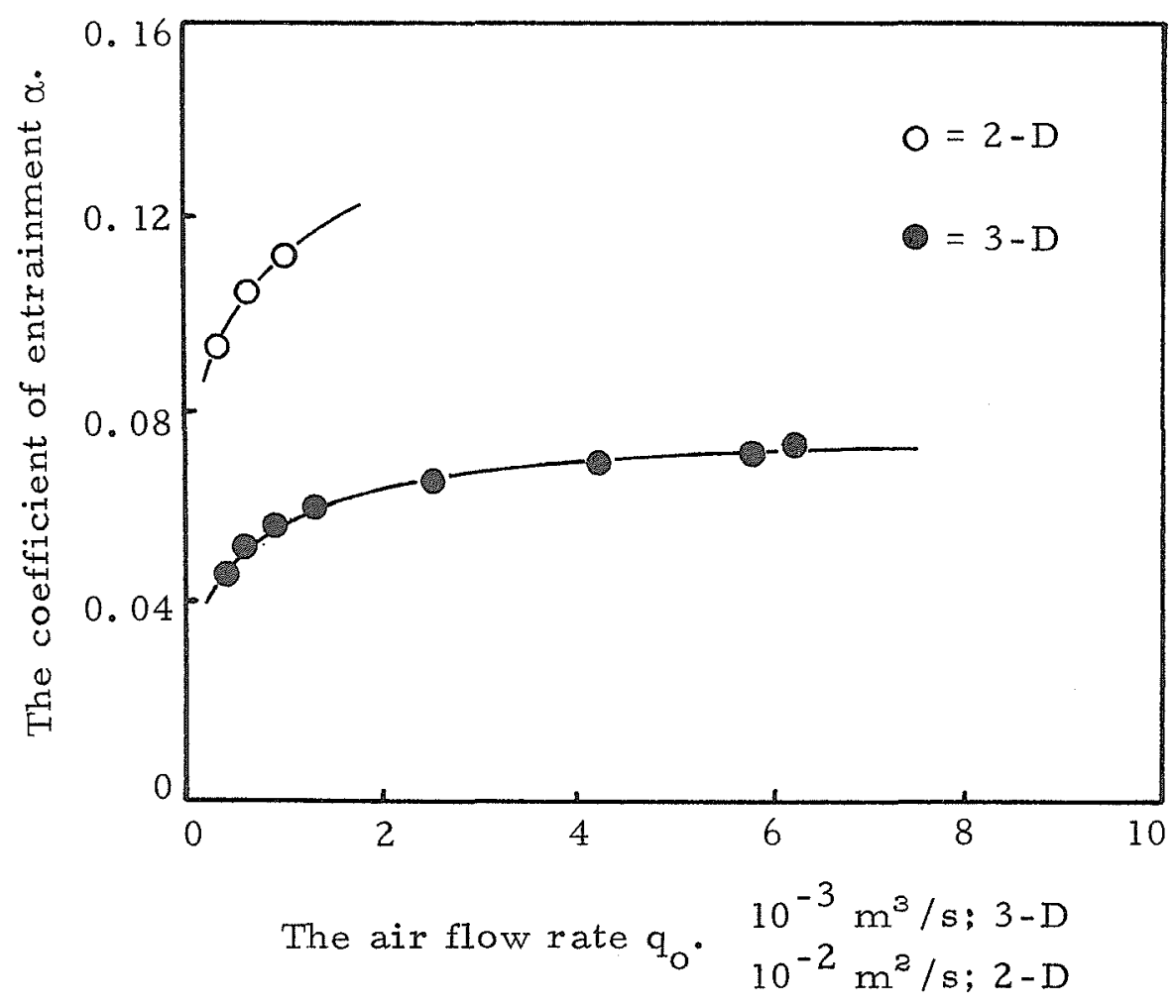

Fig. 17. The coefficient of entrainment as a function of the air flow rate for twoand three-dimensional air-bubble plumes. Experimental data by Kobus (1968). 


\section{AIR BUBBLE SYSTEMS IN STRATIFIED WATER}

Air-bubble systems are likely to be used extensively in the future for water quality management of lakes and reservoirs. Hence, a theory that predicts the circulation and mixing induced by air-bubble plumes in stratified water is very much needed. Preliminary experiments have been carried out by the senior author at Chalmers Institute of Technology to study this problem and a continuation of this investigation is planned.

The presence of a density stratification in the water gives rise to an uncoupling effect between the water flow and the air-bubbles, as shown schematically in Fig. 18 for a two-layer system. A continuous stratification may produce a similar effect.

Let us confine this discussion to a linear density profile of the ambient water and hypothesize that the governing plume equations may be developed by the same integral procedure as previously used for homogeneous water. This proposed analysis will be limited to the two-dimensional case, that is an air-curtain. The lateral velocity distribution is presumed as before to be Gaussian:

$$
\mathrm{u}=\mathrm{u}_{\mathrm{m}} \cdot \mathrm{e}^{-\mathrm{y}^{2} / \mathrm{b}^{2}}
$$

and the local density of water within the plume, $\rho_{w}$, is as sumed to have a similar variation

$$
\rho_{w}-\rho_{a}=\Delta \rho_{w} \cdot e^{-y^{2} / b^{2}}
$$

where $\rho_{a}$ is the ambient density at that particular level.

If $\mathrm{c}$ is the local concentration of air by volume we consider the lateral distribution within the plume to be given by

$$
c=c_{m} e^{-y^{2} /(\lambda b)^{2}}
$$




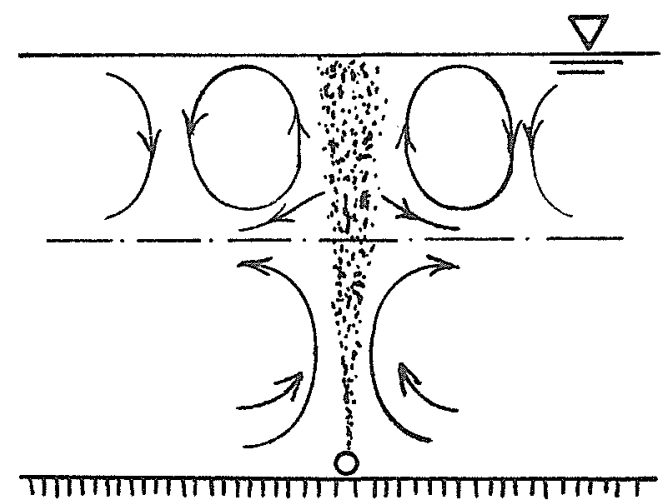

a. Complete uncoupling between plume water and air-bubbles at the interface.

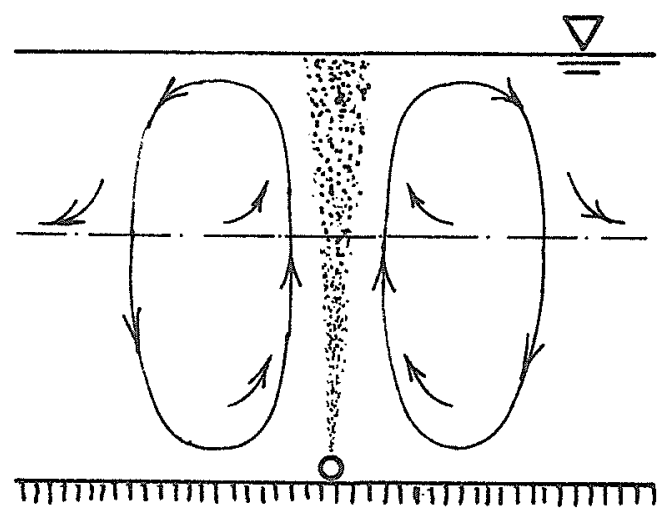

b. Partial uncoupling at the interface.

Fig. 18. Observed possible flow regimes with a bubble screen in a two-layer density system. 
The density of the air-water mixture, $\rho_{m}$, is then

$$
\rho_{\mathrm{m}}=\mathrm{c} \rho_{\text {air }}+(1-\mathrm{c}) \rho_{\mathrm{w}}
$$

The Boussinesq approximation holds for mass and momentum flux relations: $\rho_{\mathrm{m}} \approx \rho_{\mathrm{w}} \approx \rho_{\mathrm{o}}$ since $\mathrm{c}<<1$ and $\frac{\rho_{\text {air }}}{\rho_{\mathrm{w}}}=O\left(10^{-3}\right) . \rho_{\mathrm{o}}$ is the reference density chosen as the density of the ambient water at the source level.

The following equations of conservation may then be written for a line source.

1. For the volume (mass) flux

$$
\frac{d}{d x} \int_{-\infty}^{\infty} \rho_{m} u d y=2 \alpha u_{m} \rho_{a}
$$

which is reduced to

$$
\frac{d}{d x}\left(u_{m} b\right)=\stackrel{2}{\sqrt{\pi}} \alpha u_{m}
$$

The coefficient of entrainment, $\alpha$, is as before assumed to be constant.

For the air flow we have a similar relation

$$
\int_{-\infty}^{\infty} c\left(u+u_{b}\right) d y=\frac{q_{0} H_{0}}{H_{0}+H-x}
$$

which may be written

$$
c_{m}\left(\frac{u_{m}^{\lambda b}}{\sqrt{1+\lambda^{2}}}+u_{b} \lambda b\right)=\frac{1}{\sqrt{\pi}} \frac{q_{o} H_{o}}{H_{o}+H-x}
$$

2. The momentum flux equation is

$$
\frac{d}{d x} \int_{-\infty}^{\infty} \rho_{m} u^{2} d y=\int_{-\infty}^{\infty} g\left(\rho_{a}-\rho_{m}\right) d y
$$


From Eq. (92) follows

$$
\rho_{\mathrm{a}}-\rho_{\mathrm{m}}=\rho_{\mathrm{a}}-\mathrm{c} \rho_{\mathrm{air}}-(1-\mathrm{c}) \rho_{\mathrm{w}}=\left(\rho_{\mathrm{a}}-\rho_{\mathrm{w}}\right)+\mathrm{c}\left(\rho_{\mathrm{w}}-\rho_{\text {air }}\right)
$$

which is approximated to

$$
\rho_{\mathrm{a}}-\rho_{\mathrm{m}}=\left(\rho_{\mathrm{a}}-\rho_{\mathrm{w}}\right)+c \rho_{\mathrm{o}}
$$

Hence, Eq. (97) may be written

$$
\frac{d}{d x} \int_{-\infty}^{\infty} \rho_{0} u^{2} d y=\int_{-\infty}^{\infty} g\left[\left(\rho_{a}-\rho_{w}\right)+c \rho_{0}\right] d y
$$

which is reduced to

$$
\frac{d}{d x}\left(u_{m}^{2} b\right)=\sqrt{2} g c_{m} \lambda b-\sqrt{2} g \frac{\Delta \rho_{w}}{\rho_{o}} b
$$

3. The conservation of buoyancy flux.

The buoyancy flux relative to the reference density $\rho_{0}$ is split into two terms representing the two fluids.

$$
B=\left(\rho_{0}-\rho_{\text {air }}\right) \frac{q_{0} H_{o}}{H_{0}+H-x}+\int_{-\infty}^{\infty} u\left(\rho_{0}-\rho_{w}\right) d y=B_{1}+B_{2}
$$

The conservation of buoyancy flux $B_{2}$ yields

$$
\frac{\mathrm{dB} z}{\mathrm{dx}}=2 \alpha \mathrm{u}_{\mathrm{m}}\left(\rho_{\mathrm{o}}-\rho_{\mathrm{a}}\right)
$$

Eqs. (102) and (103) give

$$
\frac{d}{d x}\left(u_{m}\left(\rho_{o}-\rho_{a}\right) b \sqrt{\pi}-u_{m} \Delta \rho_{w} b \frac{\sqrt{\pi}}{\sqrt{2}}\right)=2 \alpha u_{m}\left(\rho_{o}-\rho_{a}\right)
$$


Hence, we have to solve for $u_{m}, c_{m}, \Delta p_{w}$ and b Eqs. (94), (96), (101) and (104). These equations have to be solved numerically following the same procedure as previously outlined. In addition to the scaling parameter, $P$, and the source parameter, $G$, we will now have to consider also a stratification parameter. At some level the total driving buoyancy force of the air-bubble plume may vanish. Whether there is a complete uncoupling at such a transition level or at a higher ceiling level (overshooting) or a gradual peeling off of plume water has to be studied in the laboratory.

Detailed numerical analyses and laboratory experiments are necessary to demonstrate the validity of the theory proposed above before it may be reasonably applied to field installations.

\section{CONCLUSIONS}

Experimental observations on the velocity distribution within the air-bubble plume clearly demonstrates the close relation to a simple plume of buoyancy only. In the air-bubble case the expansion of the air due to its compressibility increases the flux of buoyancy with distance from source. The differential velocity between the rising air bubbles and the ambient water has an opposite effect as it reduces the local concentration of air bubbles in the plume. Although the two effects do not cancel each other, the simple plume equations were found to be a fairly good description of the flow field at least in the three-dimensional case. The present theory, however, makes it possible to describe with sufficient accuracy the gross behavior of any air-bubble system. More experimental data are needed to establish proper values of the coefficient of entrainment and slip velocities of the air-bubbles to cover the whole range of conditions that may apply in a practical situation. Airbubble systems in stratified water will be subjected to further studies. 


\section{ACKNOWLEDGMENTS}

The writers would like to acknowledge valuable discussions with Drs. Norman H. Brooks and E. John List. For typing the manuscript we are indebted to Mrs. Arvilla F. Krugh.

This work has been supported by the Federal Water Quality Administration, Research Grant No. 16070 DGY. The first writer has had a stipend paid by the Swedish Board of Technological Development (STU) and the second writer a U.S. Public Health Service Training Grant. 


\section{REFERENCES}

Bulson, P.S.,

Bubble Breakwaters with Intermittent Air Supply. Research Report 9-2, (1962);

and

Large Scale Bubble Breakwater Experiments

Research Report 9-3 (1962)

Military'Eng. Experimental Establishment,

Christchurch, Hampshire, England.

Davidson, J. F. Bubble Formation at an Orifice in a Viscous and Schiiler, B. O. G. , Liquid. Trans. of the Inst. of Chemical Eng., Vol. 38, (1960).

Haberman, W. L. and Morton, R. K. ,

Kobus, H. E.

Lee, S. L. and

Emmons, H. W. ,

Morton, B. R.,

Taylor, G. I.

and Turner, J.S.,

Rouse, H.,

Yih, C. S., and

Humphreys, H. W.,

Sjöberg, A. ,

Taylor, G. I.
An Experimental Study of Bubbles moving in

Liquids. Proc. ASCE, Vol. '80, (1954).

Analysis of the Flow Induced by Air-Bubble Systems, Coast. Eng. Conf. Vol. II, London, (1968).

Study of Natural Convection Above a Line Fire, J. Fluid Mech., Vol. 11, (1961).

Turbulent Gravitational Convection from Maintained and Instantaneous Sources, Proc. Roy. Soc., Vol. A236, (1956).

Gravitation Convection from a Boundary Source, Tellus, Vol. 4, (1952).

Strömningshastigheter kring luft-bubbelridå i täthetshomogent och stillastaende vatten. (In Swedish), Chalmers Institute of Technology, Hydraulics Division.

Report No. 39, (1967).

The Action of a Surface Current Used as a Breakwater, Proc. Royal Soc. A, Vol. 231, (1955). 